ARCHIVO ESPAÑOL DE ARTE, LXXXII, 328

OCTUBRE-DICIEMBRE 2009, pp. 327-354

ISSN: 0004-0428

\title{
MIRADOR DE LA QUBBA MAYOR (LINDARAJA). ARMADURA APEINAZADA DE CINTAS CON VIDRIOS DE COLORES*
}

\author{
POR \\ Antonio FernándeZ-Puertas \\ Universidad de Granada
}

En este trabajo se estudia la única armadura apeinazada decorativa con vidrios de colores que ha pervivido in situ en el arte hispanomusulmán, en el palacio del Riyāẹ al-Sa īid de la Alhambra, de ahí su enorme importancia para la Historia del Arte.

Palabras clave: Armadura apeinazada, Vidrio coloreado, Arte Hispanomusulmán, Arte Nazarí, Palacio del Riyāạ al-Sa'īd, Alhambra.

This work studies the only decorative wooden ceiling with coloured glass that survived in situ in Hispano-Muslim Art, in the Palace of the Riyād al-Sa ${ }^{\text {îd }}$ of the Alhambra, hence its enormous importance for the History of Art.

Key words: Interlacing wooden ceiling, Coloured glass, Hispano-Muslim Art, Nașrid Art, Palace of the Riyāọ al-Sa īid, Alhambra.

Hacia los 1380, Muḥammad V mandó edificar el Alcázar del Riyāḍ al-Sa‘īd, o del Jardín Feliz, conocido hasta hoy por el palacio de los Leones. El ala N. del mismo la constituye la Qubba Mayor (al-Qubba al-Kubrà) que la centra una sala linterna con el nombre decimonónico de sala de las Dos Hermanas, con alcobas a E. y O., y la sala de los Ajimeces a N. En mi opinión, con posterioridad a la edificación del conjunto se le añadió a esta sala un mirador septentrional que daba hacia la ciudad de Granada, llamado por Ibn Zamrak en su Dīwān el bahw de la Qubba Mayor, y conocido ahora popularmente por Mirador de Lindaraja ${ }^{1}$. Doy una serie de razones para justificar mi opinión, las cuales voy a enumerar:

\footnotetext{
* Todos los dibujos han sido realizados por Manuel López Reche y pertenecen a mi archivo personal.

${ }^{1}$ Ibn Zamrak, Dīwān, editado por M. Tawfīq al-Nayfar, Dār al-garb al-islamī, Beirut, 1997, p. 124, cabecera del poema 90, que consta de 24 versos y está epigrafiado sobre los zócalos de alicatado de la sala-linterna de la Qubba Mayor.
} 


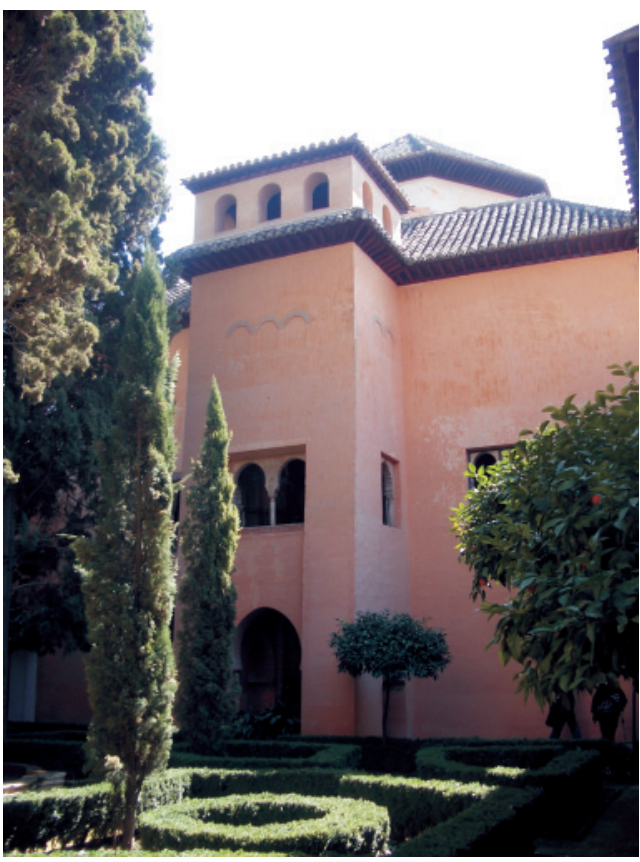

Fig. 1. Vista del Bahw o Mirador (Lindaraja).

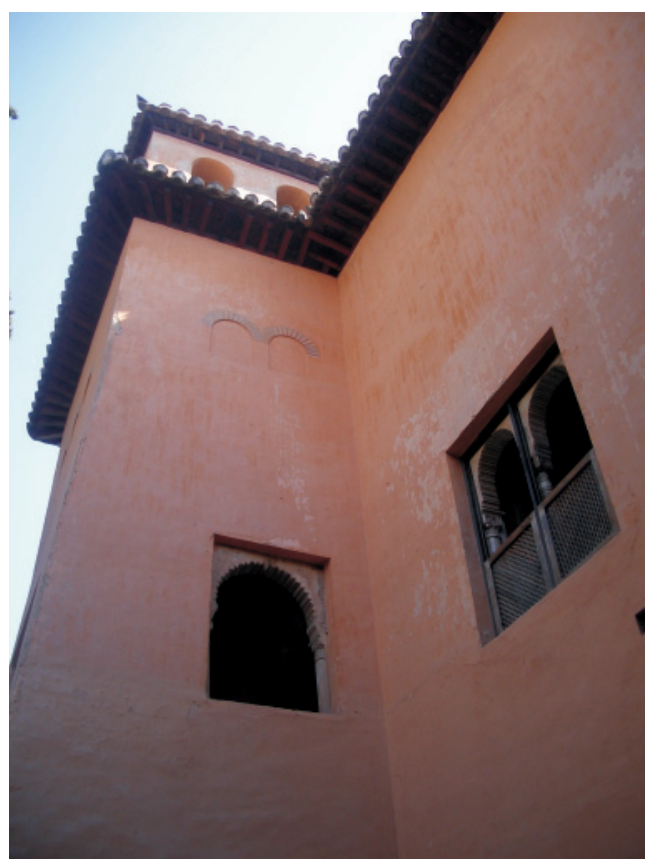

Fig. 2. Detalle de las ventanas y alero del Bahw.

1) Cuando estudié el trazado proporcional del palacio del Riyāḍ al-Sa 'īd $\mathrm{d}^{2}$ comprobé que el conjunto del trazado del edificio palatino tiene una unidad que llega hasta la sala de los Ajimeces, y que el bahw o mirador, fue un añadido, como se ve por su proximidad a las ventanas E. y O. con dos arcos sobre columna parteluz de esta sala, que debió de tener una tercera ventana también de dos arcos con columna parteluz en el lugar en que se halla el arco de acceso al actual mirador (figs. 1-4). Esto mismo ocurre en la sala N. de la Casa Real de la Felicidad (Dār al-Mamlaka al-Sa‘ida) en la finca del Generalife ${ }^{3}$.

2) El conjunto de la Qubba Mayor está edificado sobre una planta abovedada. Tiene una estancia central cuadrada rodeada por un primer pasillo deambulatorio y otro segundo en forma de "U", con un luneto abierto hacia la parte baja del mirador, el cual muestra a la vista un techo plano dispuesto a dos niveles, salvados por moldura de nacela (figs. 6, 7). En la planta baja los lados del bahw E., O. y N., tienen un arco apuntado de herradura que arranca de impostas voladas en nacela (figs. 1, 5).

3) Por el hecho de estar adosado a la sala de los Ajimeces y no formar parte de los muros perimetrales palatinos desde origen, el mirador se separó por desplome ya en época temprana. Ello explica la pérdida de los versos 1 y 13 del poema de Ibn Zamrak de trece versos que se halla epigrafiado en los alfices de sus arcos ${ }^{4}$. Esta opinión mía se puede confirmar o desestimar con sólo

\footnotetext{
${ }^{2}$ Fernández-Puertas, Antonio: The Alhambra, I. From the Ninth Century to Yüsuf I (1354), Londres, Saqi Books, 1997, pp. 63-65, figs. 50-51. Éste es el nombre original "Alcázar del Jardín Feliz", del denominado hoy palacio de los Leones por la famosa fuente de su patio. FernándeZ-Puertas, A.: "El arte", en El reino nazarí de Granada (12321492). Sociedad, vida y cultura, vol. VIII-IV, de la Historia de España, Espasa Calpe, Madrid, 2000, p. 248.

${ }^{3}$ Fernández-Puertas, A.: The Alhambra, I, p. 12, fig. 4a, 4b. A. FernándeZ-Puertas, "El arte", pp. 214-220, fig. 4, 4b en p. 197.

${ }^{4}$ Fernández-Puertas, A.: Vida palatina en la Alhambra. Textos árabes de Ibn al-Ŷayyāb, Ibn al-Jațīb e Ibn Zamrak que describen el Qașr al-Sulțān (Comares), el Qașr al-Riyād al-Sa '̄̄d (Leones) y otros edificios regios, edición
} 
quitar el enfoscado en los ángulos de unión de los muros E. y O. del mirador con la sala de los Ajimeces por el patio-jardín de Lindaraja y ver cómo se unen entre sí los muros (figs. 1 y 2).

4) Además, estimo que el bahw fue un adosado posterior porque su planta proporcional es un rectángulo $\sqrt{2}$ que no entra dentro del trazado general del palacio.

En el mirador de la Qubba Mayor las manifestaciones artísticas del Alcázar del Riyāḍ al-Sa ‘̄id alcanzan su pleno auge (figs. 3, 4). En los lazos rectilíneos de sus alicatados, aparece una traza grande de color que incluye a otra muy pequeña con cinta entre sus piezas ${ }^{5}$; otra traza de estrella de ocho puntas de $90^{\circ}$ superpuesta a una idéntica, por lo que las crucetas de ambas quedan en el centro del campo de las estrellas; y un lazo mixto de difícil diseño a base de ruedas de $12 \mathrm{com}$ binadas con otras de 9 . En el decorado a base de yesería, hay temas de ataurique de superficie convexa. Destaca el bien caligrafiado tulut de su poema de los alfices de los arcos de las ventanas. Alcanzan su cenit las inigualables composiciones en escritura cúfica con fantástico desarrollo de sus cintas de prolongación dispuestas con rigurosa simetría axial. Son únicos, en diseño y composición, los apuntados arcos de mocárabes en plano saliente, trasdosados por otros de lóbulos. En la parte alta figura el tema de lazo curvo con ataurique. Cubre esta maravillosa estancia la armadura apeinazada de cintas con vidrios de colores que se estudia a continuación.

En 1691, el mirador acusaba inminente ruina, según recoge la documentación del Archivo de la Alhambra ${ }^{6}$. Una sólida reforma se realizó en 1853 por Rafael Contreras Muñoz (1847-1882) como se explica más abajo, quien ataludó la base de la construcción y retocó los arcos de herradura del mirador, cuyos ladrillos fueron policromados en rojo con tendeles blancos (figs. 1, 5) ${ }^{8}$. En 1879-1880 Rafael Contreras Muñoz y en 1883-1884 con su hijo el arquitecto Mariano Contreras Granja se restauraron las yeserías y la solería del mirador ${ }^{9}$. Así, pues, en la planta de sótanos abovedados, el mirador tiene arcos de herradura apuntados en sus frentes. A la altura de la planta del palacio, tiene el bahw doble arco sobre columna parteluz a N., y uno sólo a E. y O. (figs. 3, 4). Por encima, a la altura donde hoy se halla la decoración de yesería en el interior de la estancia, muestra por el exterior un cuerpo de arquitos de medio punto con rosca de ladrillo pintado y pilar entre ellos cegados, todos a la misma altura, tres hacia N. y dos hacia E. y O. (figs. 1, 2). El mirador tiene un alero en tornapunta a la altura del de la sala de los Ajimeces con solución angular propia del si-

bilingüe español-inglés, en prensa. El verso 1 lo sustituye un vaciado del 9 y el verso 13 uno del 4, es decir, los colocados en el lado opuesto de las diagonales de la planta rectangular del mirador.

${ }^{5}$ Este tipo de lazo se encuentra en los zócalos de alicatado del patio de las Doncellas del Alcázar de Sevilla, hechos por artistas nazaríes también con anterioridad.

${ }^{6}$ En un reconocimiento de los palacios hecho en 1691 se escribe que "está desplomado y amenazando breve ruina", por lo que era necesario recalzar su parte baja aunque ya tenía tirantes de hierro. Esta obra se efectuó poco después, Legajo 211 de la antigua numeración del Archivo de la Alhambra y 229 de la nueva; cfr. Moreno Olmedo, María Angustias: Catálogo del Archivo Histórico de la Alhambra, Patronato de la Alhambra, Granada, 1994, p. 631.

${ }^{7}$ El señor F. J. Serrano Espinosa me ha facilitado los datos de que Rafael Contreras fue nombrado "Restaurador Adornista de la Alhambra" por Real Orden de 12 de marzo de 1847. Después, por Orden Ministerial, en 1872, fue designado "Director de la Restauración de las Obras de la Alhambra". Rafael Contreras Muñoz. Restaurador Adornista de la Alhambra. 1824-1890, Granada, 2009.

${ }^{8}$ Rafael Contreras Muñoz realizó en 1853 una reparación en los arcos de la parte baja abovedada y restauró la armadura decorativa apeinazada de la que especifica que halló restos y fragmentos de los vidrios originales. Dice: "En el año 1853 se fortificaron los muros por el exterior para contener la ruina indicada en la antesala inmediata. En ella se notan dos preciosos ajimeces que abren al patio citado"; sobre la armadura apeinazada decorativa de cintas escribe: "Tan preciosa estructura [del mirador] está coronada por una tracería calada hecha de madera, y en cuyos claros había colocados cristales de colores (1)". En la nota 1 indica que: "Los hemos hallado nosotros con motivo de nuestras obras, y conservamos fragmentos". CONTRERAs, Rafael: Estudio descriptivo de los monumentos árabes de Granada, Sevilla y Córdoba, o sea, la Alhambra, el Alcázar y la Gran Mezquita de Occidente, Madrid, 1875, p. 270.

${ }^{9}$ Archivo de la Alhambra, L-345, L-346. 


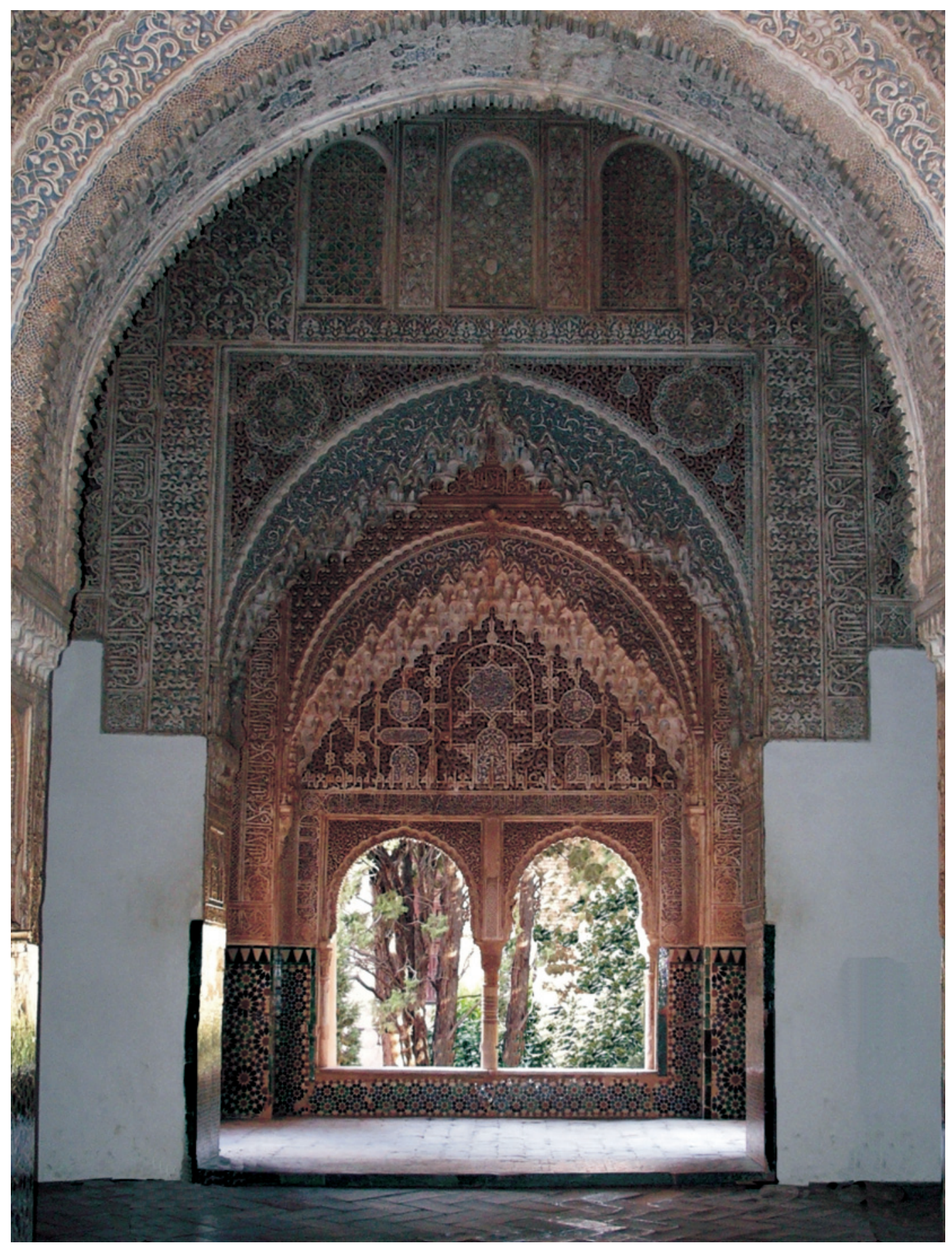

Fig. 3. Vista frontal del Bahw desde la Qubba Mayor; entre medias la sala de los Ajimeces. 


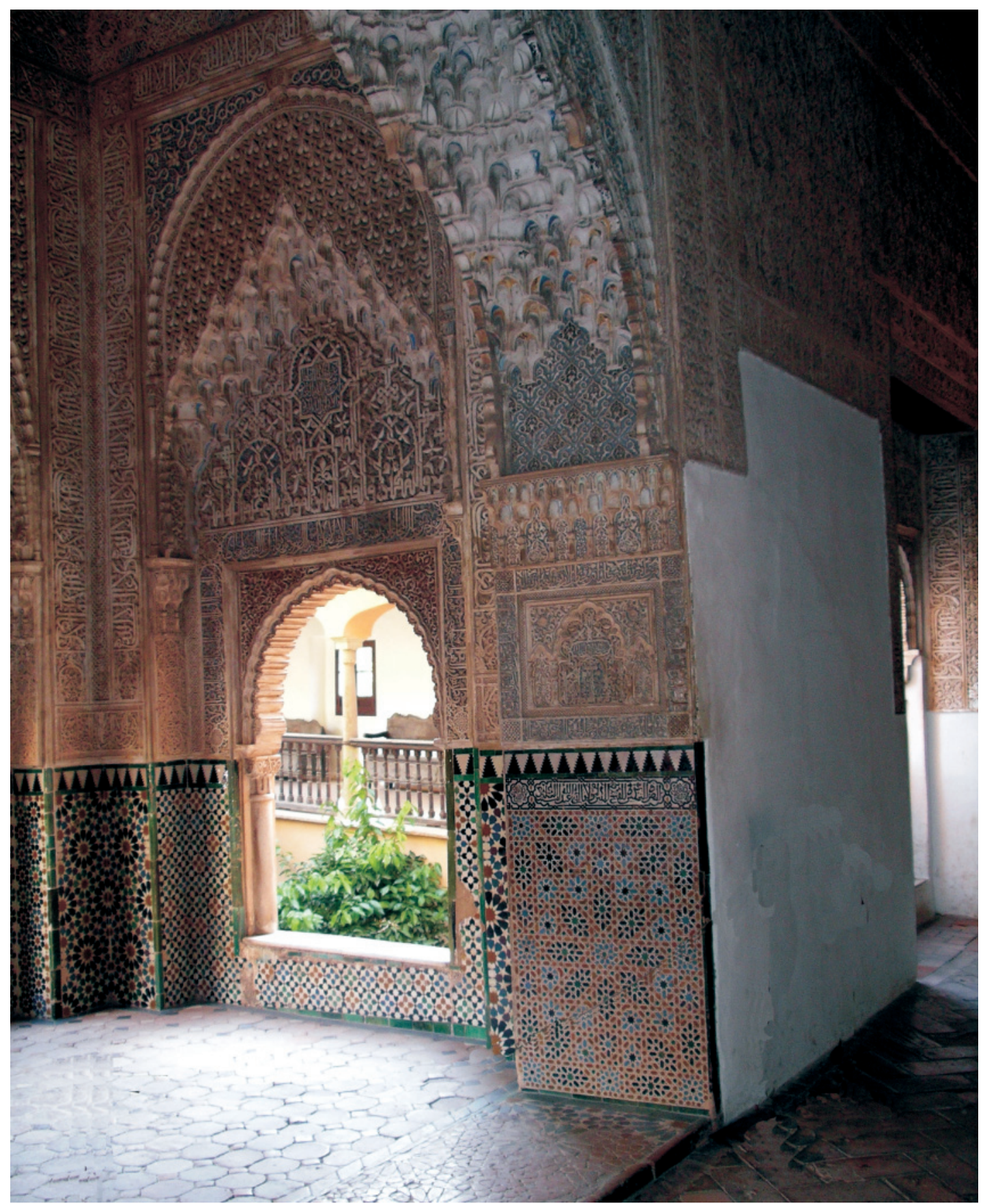

Fig. 4. Vista en diagonal del interior del Bahw o Mirador desde la sala de los Ajimeces. 


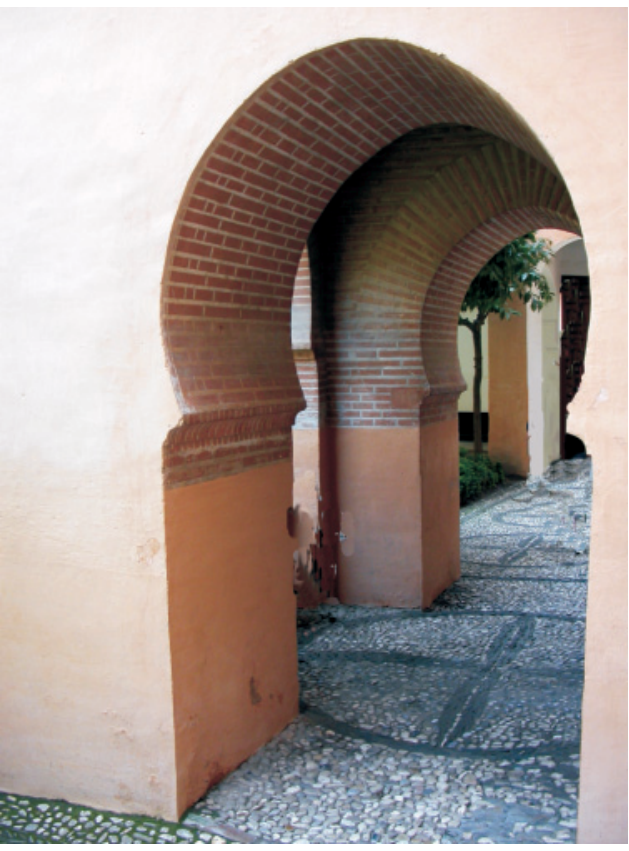

Fig. 5. Planta baja del Bahw que descansa en arcos de herradura apuntada. Se proyecta dentro del jardín del llamado patio de Lindaraja.

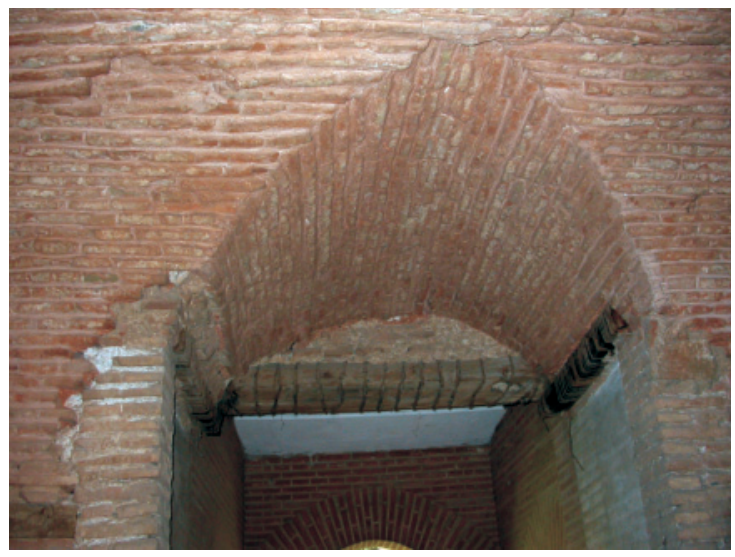

Fig. 6. Luneto del área abovedada de la Qubba Mayor.

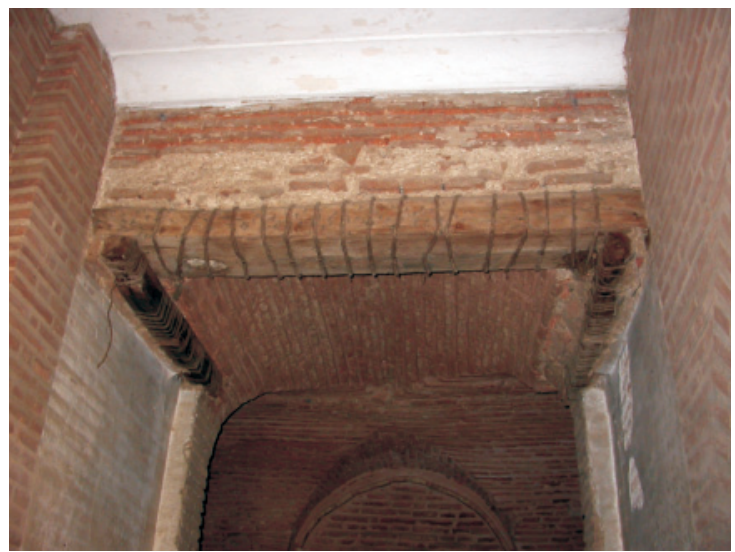

Fig. 7. Luneto y techo plano bajo el Bahw o Mirador.

glo XIV (fig. 2), que se halla también en el llamado patio del Harem, o vivienda alta a O. de la Qubba de Poniente (al-Qubba al-Garbiyya) (figs. 1, 2, 8), así como en otros aleros nazaríes.

En mi opinión, cuando se decidió construir el $b a h w$, éste fue concebido en un principio hasta la altura de estos arquitos ciegos que dan hacia el exterior, donde hoy se ven. Dicha hipótesis se podría comprobar o desechar con sólo hacer una prospección desde el exterior en uno de estos arcos y ver si fueron en origen concebidos huecos para albergar celosías o bien sólo como ornamentación exterior. En un segundo momento el arquitecto pensó dar al mirador un cuerpo lucernario no a través de ventanas con celosías, sino mediante la armadura decorativa apeinazada con vidrios entre sus cintas (figs. 8-23). De este modo, la luz no entraba de modo horizontal por las celosías (como es lo normal en los palacios y casas nazaríes), sino que bajaba en diagonal desde lo alto, hasta la armadura decorativa (figs. 8, 16). Debido a esto, edificó un cuerpo lucernario con tres altas ventanas con arcos semicirculares a septentrión, dos a naciente y dos a poniente, hoy día abiertas y sin celosías. Los huecos semicirculares de las ventanas por el interior, tienen mayor altura que por el exterior y están cegados en parte de su grosor por tabiques de ladrillo plano, lo cual se debe por un lado al tejaroz sobre el alero que discurre a la altura del de la sala de los Ajimeces (figs. 1, 2, 16). 


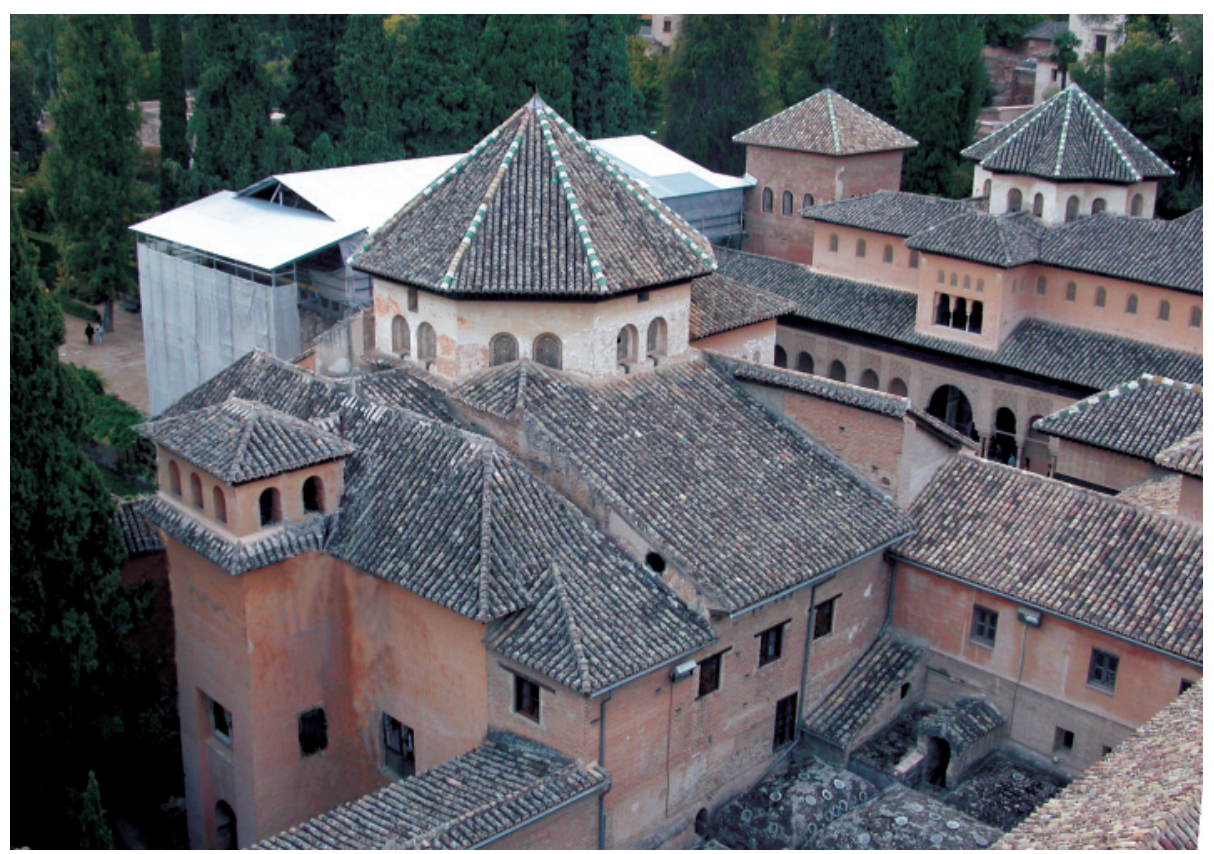

Fig. 8. Qubba Mayor con la sala de Ajimeces, el Bahw y salas colaterales. Solución de tejados actual.

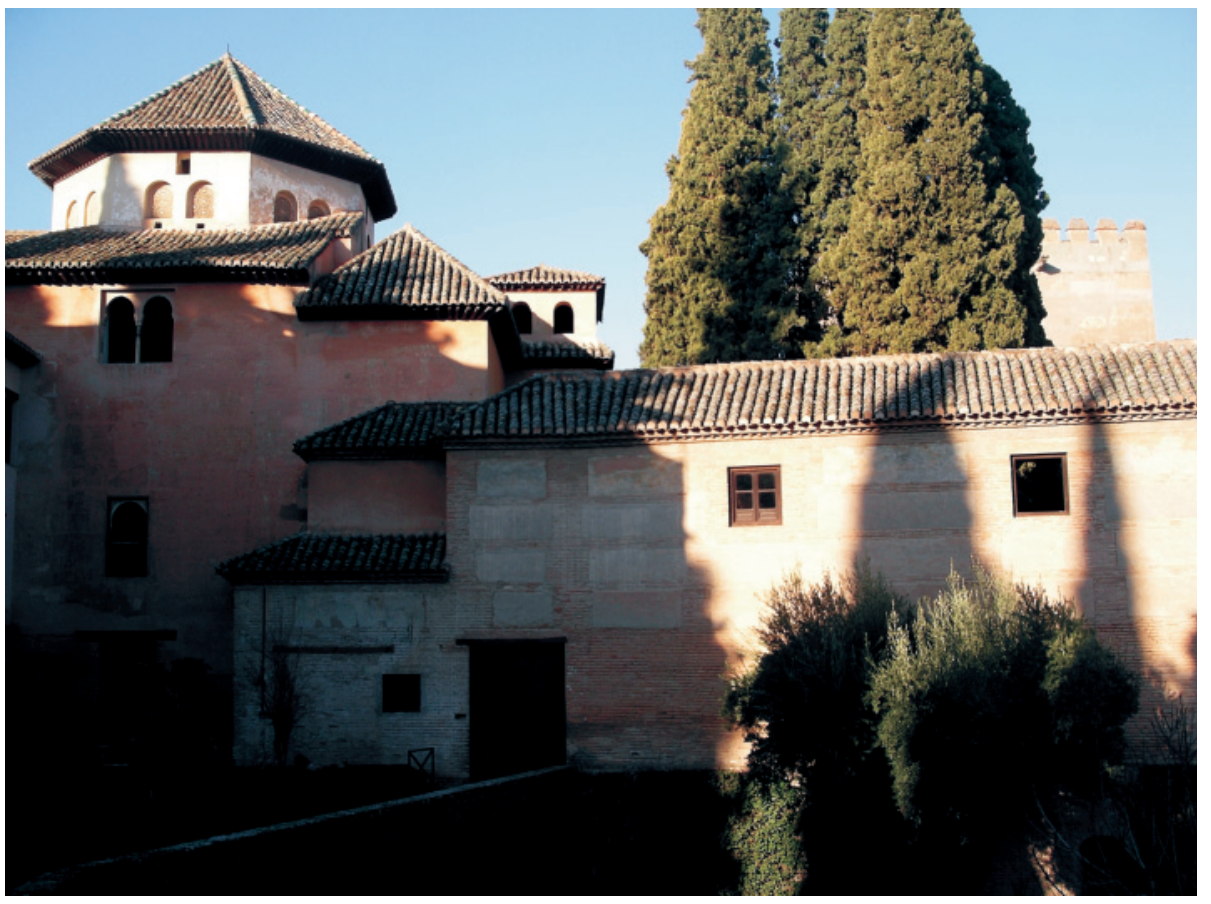

Fig. 9. Qubba Mayor: salas colaterales, la sala linterna octogonal; sala de los Ajimeces y Bahw. 


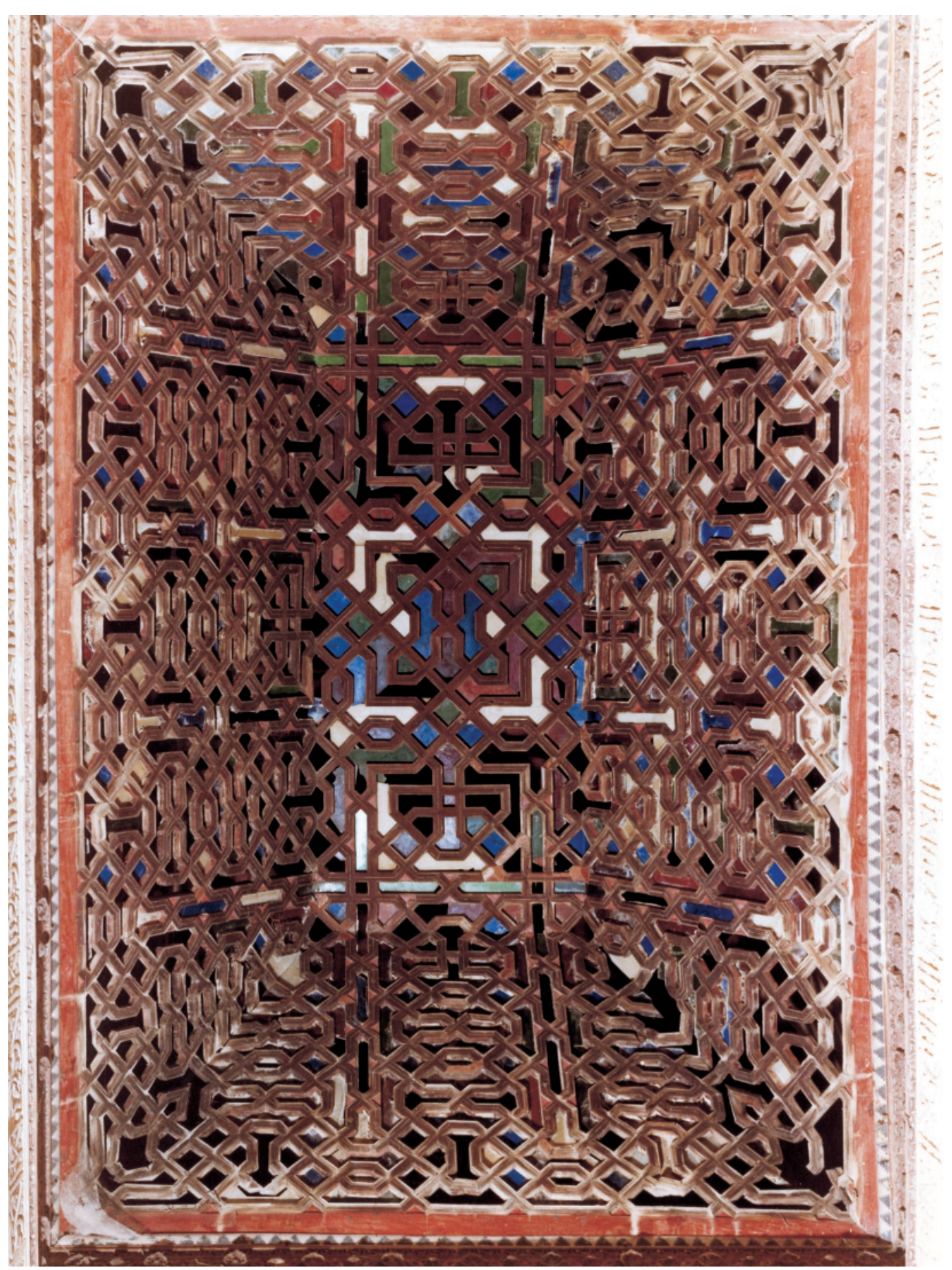

Fig. 10. Vista general de la armadura apeinazada con vidrios de colores. 
Fig. 11.A. Estructura de sujeción de los vidrios a los peinazos, vistos en sección y en su cara frontal con las ranuras de sus gramiles.

Fig. 11.B. Estructura de refuerzo colocada en 1853 a la armadura apeinazada.
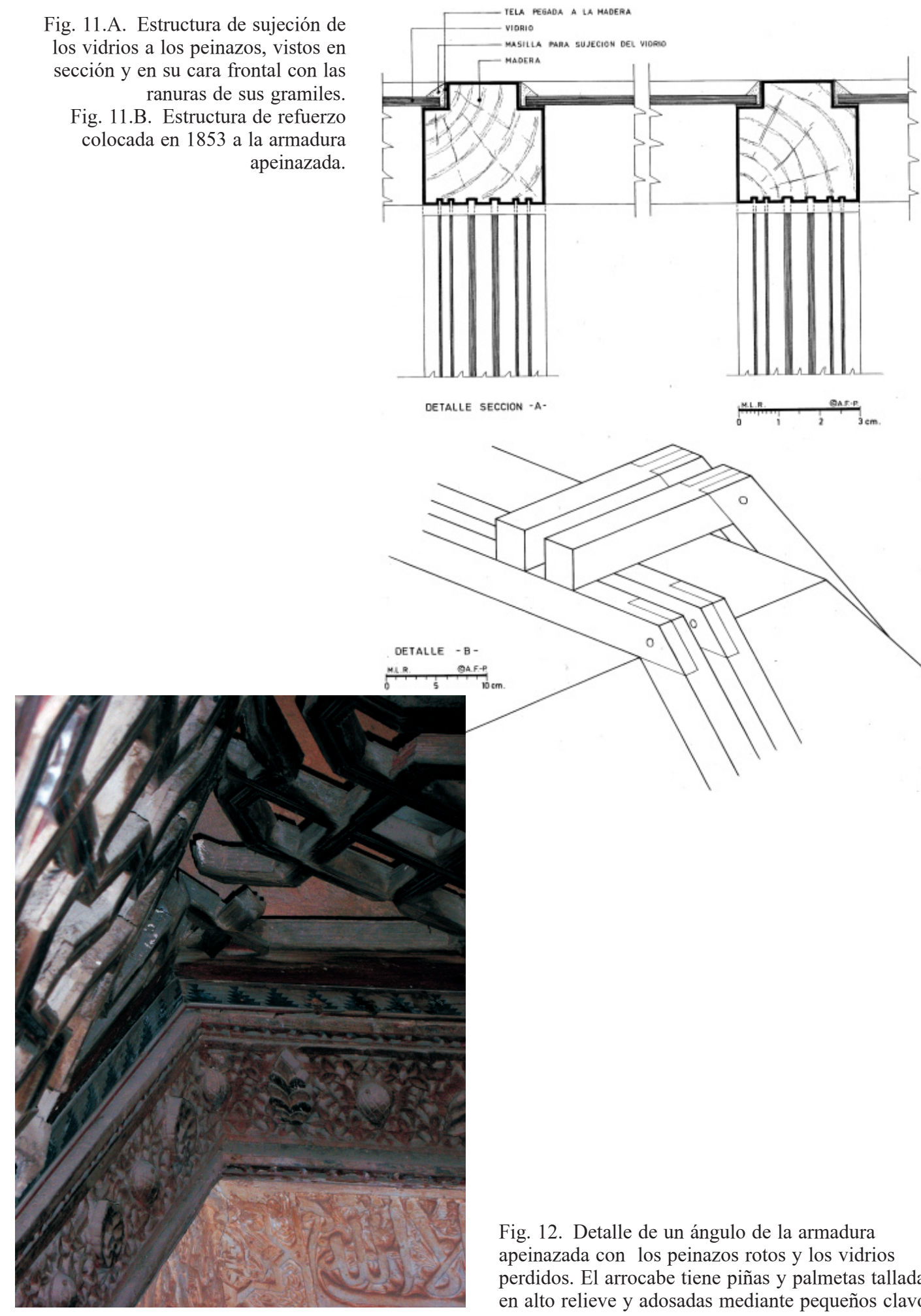

DetalLE SECcion - A-
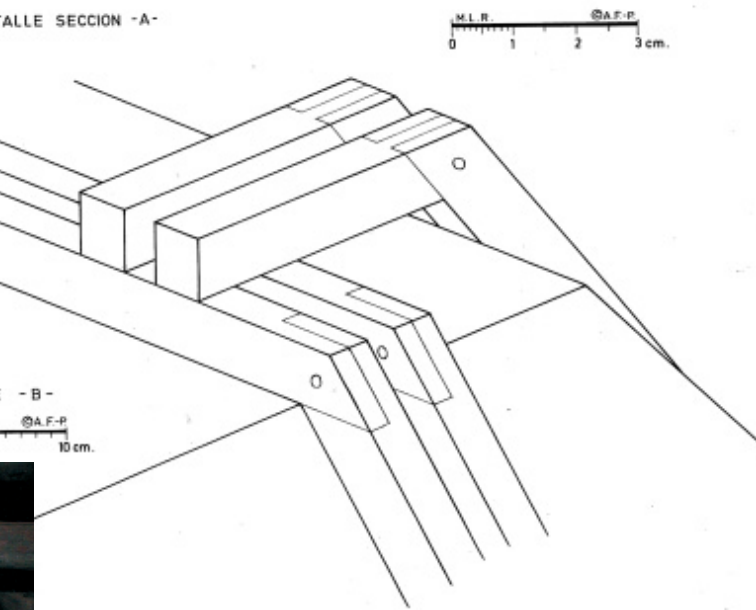

Fig. 12. Detalle de un ángulo de la armadura apeinazada con los peinazos rotos y los vidrios perdidos. El arrocabe tiene piñas y palmetas talladas en alto relieve y adosadas mediante pequeños clavos. 
El cuerpo lucernario tiene cubierta a cuatro aguas que sobresale por encima del de la mencionada sala, lo cual no es una buena solución de cubiertas, pues su lado sur echa las aguas al tejado N. de la sala de los Ajimeces (figs. 1, 8, 9). Para evitar la humedad y los recalos se ha practicado una canalización de desvío hacia los extremos del cuerpo lucernario del mirador, el cual tiene ciego su muro por su lado meridional. Lo lógico hubiera sido tener una cubierta a tres aguas, con un paño triangular a N. y trapezoidales a E. y O., unida a la de la sala de los Ajimeces, como hace el templete $\mathrm{O}$. del patio de los Leones con la galería de poniente (fig. 8 a la derecha), y también lo hacía el templete E. con la galería de naciente hasta la intervención de Rafael Contreras Muñoz en 1859, según el testimonio de las fotografías de Davillier, Clifford y Louis de Clerq, como me ha mostrado mi amigo y colega el arquitecto Carlos Sánchez Gómez.

En mi opinión, en época hispanomusulmana, la Qubba Mayor cubría su sala linterna con un tejado central a ocho aguas como hoy día. A E., O. y N. lo hacía con tejados de un faldón trapezoidal. El del lado septentrional cubría la sala de los Ajimeces y de su centro hubo de salir el de tres aguas del bahw de la Qubba, como lo hace hoy el del pabellón O. del patio de los Leones.

Rafael Contreras Muñoz -al igual que hizo en la sala de los Reyes-, quiso que los volúmenes de las estancias interiores se manifestaran al exterior por tejados modulares independientes (figs. 8, 9). Esto llevó a una solución al exterior muy lograda por su estética, pero por su estructura y disposición un desastre arquitectónico para evacuar las aguas rápidamente y evitar recalos y humedades en el palacio. En el 2006 se ha comenzado una labor de restauración en la llamada sala de los Reyes, como se ve en la figura $8^{10}$. Esperemos que no se repita la solución romántica de 1859.

Se compuso la planta del mirador de la siguiente manera. Dado el ancho necesario para una holgada estancia en el mirador, y proporcionado también para no ahogar las ventanas laterales de la sala de los Ajimeces, se ha construido un cuadrado y con su diagonal $\sqrt{ } 2$ se ha obtenido la longitud del mirador (fig. 10:1). Se cubre esta estancia por la única armadura decorativa de tres paños de peinazos entrelazados, posiblemente de madera de pino, formando un lazo de cintas cuyo fondo queda calado y se rellena por vidrios de colores (figs. 10, 11, 13, 16, 18-22). Por encima de esta armadura está el camaranchón con el cuerpo clarestorio de ventanas, dos por los lados E. y O. y tres por el N., y encima la armadura estructural con el tejado (figs. 1, 3, 8, 9). En 1981, Manuel López Reche y yo examinamos por el trasdós y el interior esta armadura: tomamos los datos y fotos necesarios y él realizó para mí en su tiempo libre los planos que se publican aquí.

A continuación ofrezco el estudio del trazado proporcional de la armadura decorativa apeinazada con sus vidrios entre sus cintas entrelazadas (figs. 10-12).

1) Sobre esta planta proporcional de rectángulo $\sqrt{2}$ el artista carpintero hizo su armadura decorativa, para lo cual dividió su ancho en tres partes iguales (fig. 10:2).

2) Tras ello tomó el tercio central como almizate o parte central plana de la armadura paralela al suelo.

3) Seguidamente desde los ángulos de la planta del rectángulo $\sqrt{2}$ trazó ángulos a $45^{\circ}$ con la escuadra hasta que se cruzan para formar un ángulo de $90^{\circ}$ (fig. 10:3). Luego, por el vértice de estos ángulos de $90^{\circ}$, trazó un eje longitudinal E.-O. y otro trasversal N.-S.

4) A continuación, dividió en cuatro partes iguales el tramo del eje longitudinal que queda entre los vértices de las escuadras dibujadas en el paso 3, y se tomaron dos de estas partes como lado de un cuadrado (fig. 10:4).

${ }^{10}$ Sería muy conveniente para el buen mantenimiento de los tejados eliminar todos los cipreses próximos al testero E. de la sala de los Reyes sembrados en el Partal y los del patio de Lindaraja y sustituirlos por árboles de copa baja (como naranjos, limoneros, granados), pues la suciedad que provocan los cipreses con sus hojas y frutos atora las canales y sus desagües. L. Torres Balbás al sembrarlos durante los 13 años y 4 meses que estuvo como arquitecto de la Alhambra no se dio cuenta del daño que al monumento provocaría cuando crecieran. 


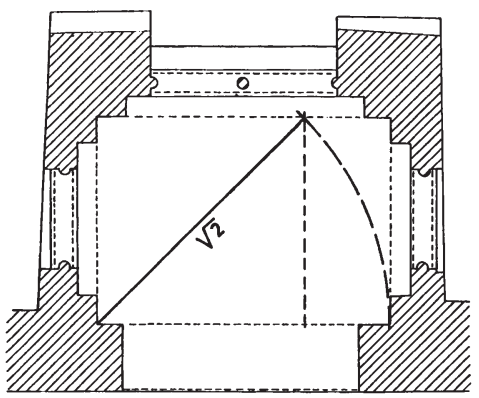

(1)

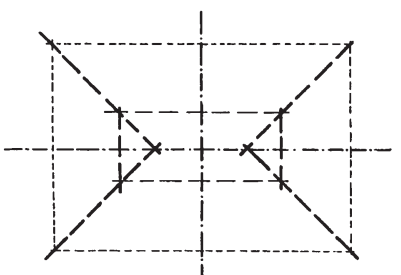

(3)

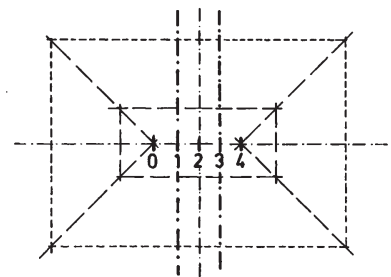

(4)

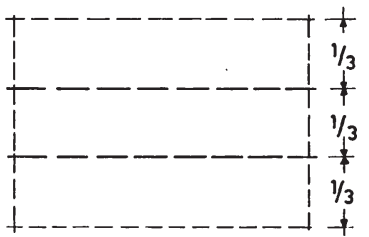

(2)

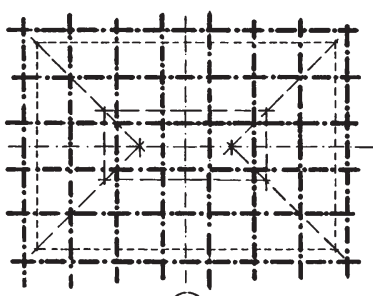

(5)

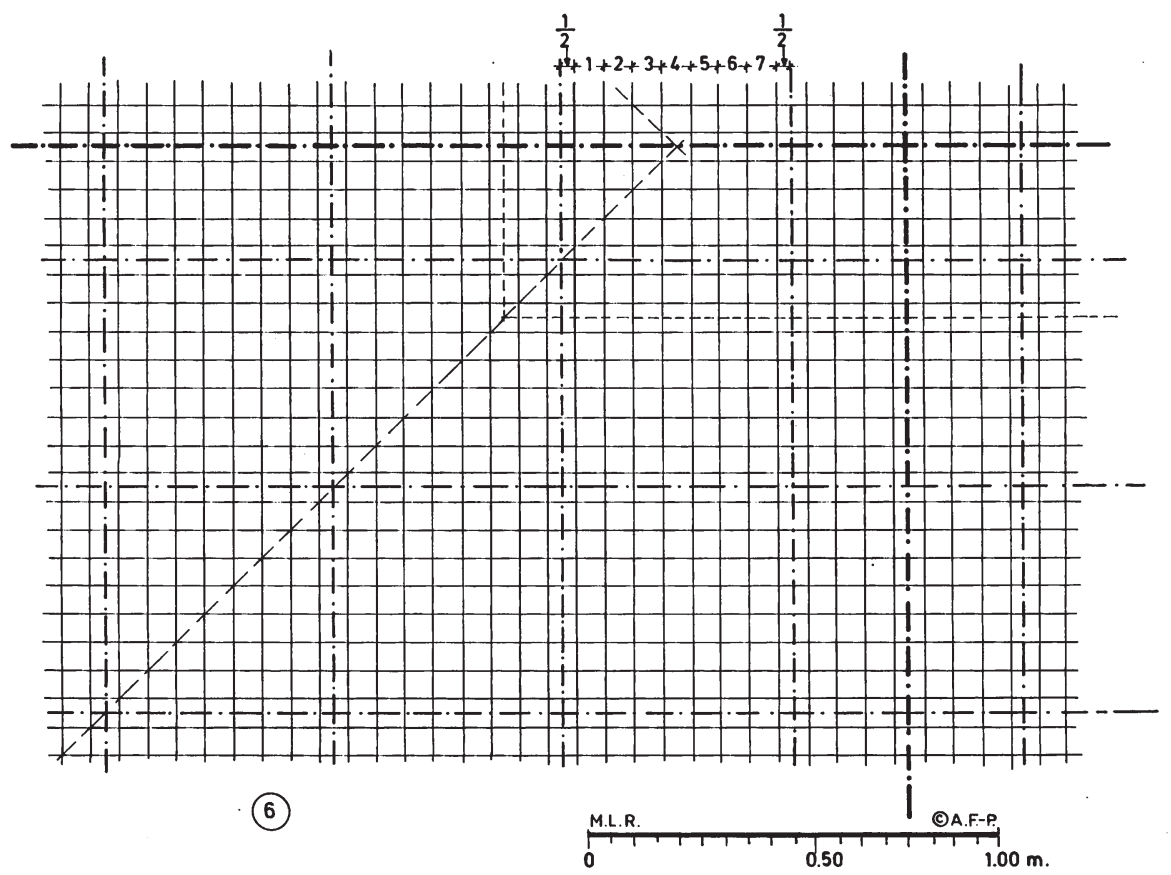

Fig. 13. Planta rectangular del Bahw o Mirador. Primeros pasos para la obtención de su armadura. 


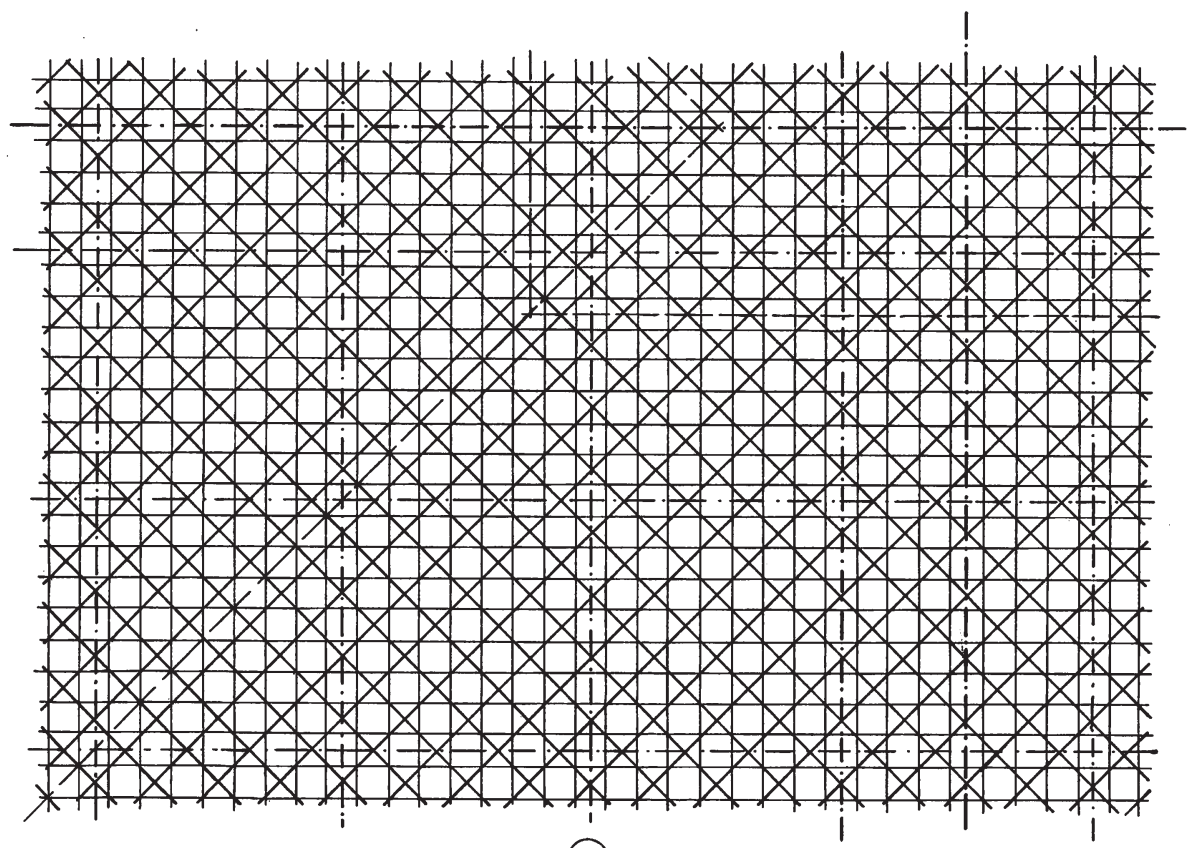

(7)

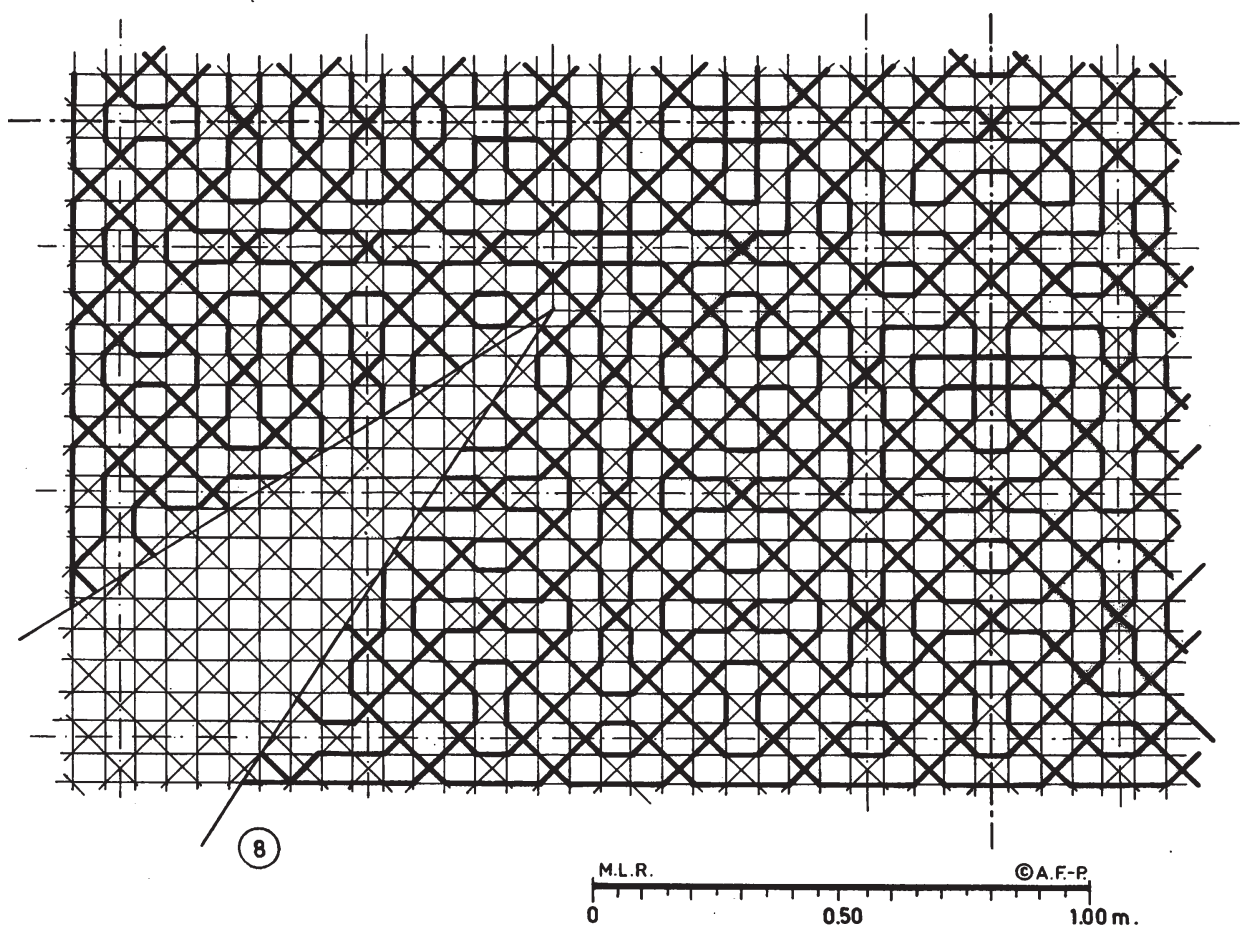

Fig. 14. Pasos 7 y 8 para la obtención de la armadura apeinazada de cintas entrecruzadas. 


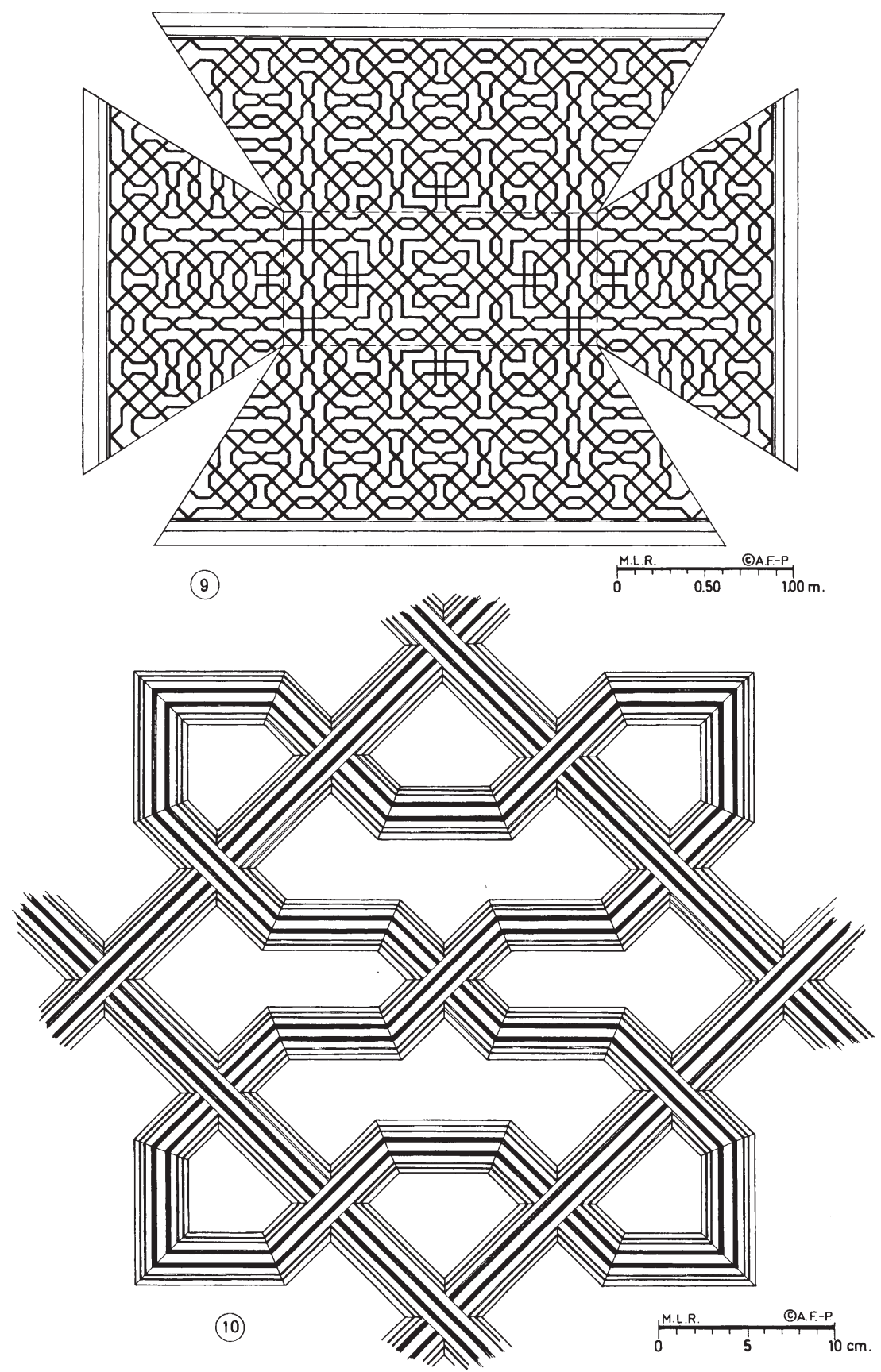

Fig. 15.9. Dibujo geométrico de la armadura apeinazada abierta por los ángulos. 15.10. Detalle central. 
5) Con posterioridad se diseñó la correspondiente cuadrícula (fig. 13.5), la cual abarcó algo más del rectángulo de la planta $\sqrt{2}$, por lo que se han prolongado sus extremos como se ve en el dibujo.

6) De ahora en adelante se va a utilizar para el estudio de la armadura la cuarta parte del rectángulo $\sqrt{2}$ dibujado a doble escala con objeto de que se pueda ver mejor el trazado (fig. 13.6). Se toma uno de los cuadrados de la cuadrícula hecha en el paso 5 y se divide en ocho partes de modo que en los extremos quede media y media parte, y entre ambas las siete restantes (fig. 13.6). Estas medias partes al unirse con las de los cuadrados contiguos, forman partes completas, y se diseña, dada esta división, una cuadrícula de menor tamaño (fig. 13.6).

7) A la pequeña cuadrícula dibujada en sentido normal en el paso 6, se le traza otra mayor girada a $45^{\circ}$ con sus cuadrados que tienen doble superficie que la primera (fig. 14.7).

8) Se procede a reforzar las líneas que interesan en el trazado geométrico del lazo de cintas en la cuarta parte de la armadura apeinazada. A renglón seguido se le dan los cortes al dibujo en el ángulo (quedan las cuadrículas sin dibujo en negro reforzado, fig. 14.8), y se forma la arista de la esquina de la armadura decorativa de los paños, la cual no tiene limas ni refuerzos angulares.

En el dibujo completo (fig. 15) se ve el almizate central con sus cuatro faldones desplegados y los cortes de sus cuatro ángulos (figs. 10, 12, 15-21). Es una labor de lazo de cintas que cierran sobre sí mismas formando figuras poligonales más o menos complejas como hexágonos, octógonos, o las uniones de unos con otros con figuras quebradas en ángulos de $45^{\circ}, 90^{\circ}$ y $135^{\circ}$, siempre en relación con las cuadrículas. Es un simple y sencillo lazo de cintas, típico de la época de Muhammad V durante la construcción del palacio del Riyāọ al-Sa‘īd.

9) He aquí el detalle central del almizate con los cortes y el despiece de los peinazos, los cuales presentan en su centro dos ranuras, o perfiles, paralelas más anchas y a cada lado otros dos perfiles, más estrechos, todos hechos mediante el gramil (figs. 10, 11A, 19). Al trabarse entre sí la labor de cintas, siguen siempre la ley del lazo de pasar una vez por encima y otra por debajo, y así hasta el infinito. Los peinazos están cortados perfectamente con sierra, en ángulo y ensamblados entre sí. Al entrecruzarse las cintas las dos ranuras centrales anchas pasan por encima o por debajo del otro peinazo, pero los dos pares de gramiles colaterales nunca lo hacen (fig. 15.10).

10) En la base de esta armadura apeinazada calada, hay un arrocabe tallado en el que se han clavado palmetas agallonadas y piñas mirando hacia abajo, dispuestas las unas y las otras de modo alterno (fig. 12). Palmetas y piñas están labradas en alto relieve, y entre ellas aparecen tallos espirilíneos con frutos con cáliz y cogollo desarrollado, que denomino pimiento. Cerca de un ángulo, en vez de palmeta hay un cogollo con cuatro cálices enroscados. Por encima discurre un estrecho friso pintado con almenas negras dentadas en la base contrapeadas por blancas, las cuales están en tan perfectas condiciones de color que parece que han sido retocadas en la reparación de 1853 por Rafael Contreras Muñoz. Cuando se restaure esta armadura apeinazada ornamental de cintas, se verá si esto es cierto, así como otras dudas que dejo en el tintero. Y, a continuación, según mi opinión, una franja moderna de madera de pino que se colocó cuando se hizo la estructura de soporte, que se estudia más abajo. En estos maderos de pino, sin policromía y que bordean toda la armadura, se encastran y apoyan los peinazos de la armadura original (figs. 10, 12). La figura 19 muestra el almizate completo, la 20 el lado trapezoidal menor de la armadura, y la 21 el lado mayor.

11) Esta armadura apeinazada - cuyo fondo entre las cintas se rellena con vidrios de colores dispuestos con simetría según los ejes longitudinal y trasversal- tiene en la actualidad una estructura de soporte que ha sido colocada por Rafael Contreras en 1853, ya que muestra puntillas o clavos con cabeza redonda plana como se utilizan en época moderna. La actual estructura de soporte es posible que sustituyera a otra original en muy mal estado; pero también cabe la posibilidad de que, en origen, la armadura apeinazada no tuviera soporte auxiliar alguno, como yo pienso. Cuando se restaure se 


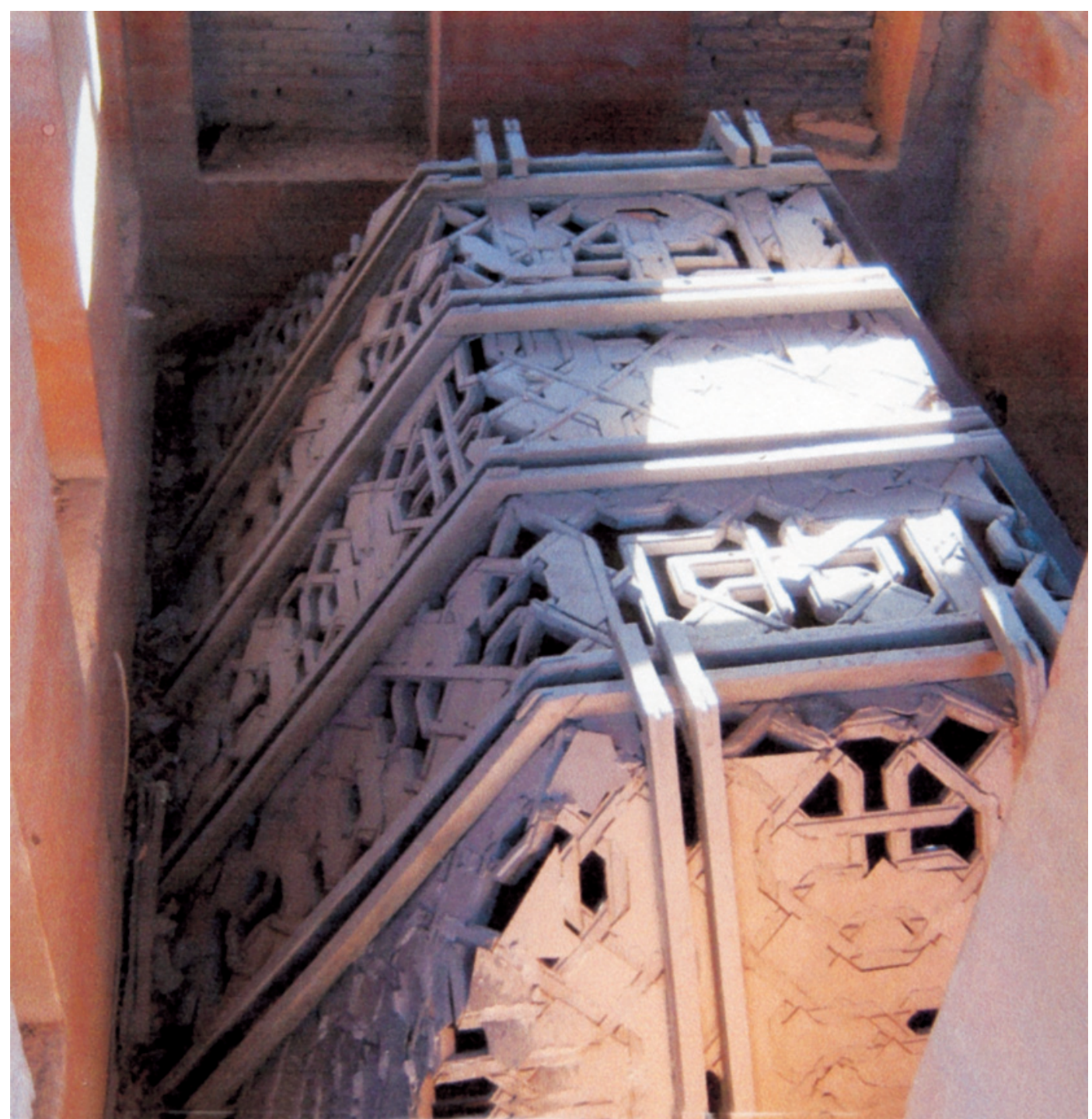

Fig. 16. Trasdós de la armadura apeinazada, con su refuerzo de 1853 y estado de conservación.

verá la solución original. Manuel Gómez-Moreno, en 1892, en su Guía de Granada, escribe sobre esta armadura que "es de cintas de madera formando lazo, entre las cuales habría vidrios de colores, pues de ellos subsistían fragmentos cuando se pusieron los actuales"11. Esta labor de armadura con peinazos coloreados y vidrios de colores entre sus huecos geométricos, obedece a la estética y técnica del lazo que introducen los maestros artísticos bajo Muhammad V a base de cintas entrecruzadas dibujadas sobre dos cuadrículas, una normal y otra sesgada. Así se ve en los zócalos con dos tipos de

${ }^{11}$ Gómez-Moreno, Manuel: Guía de Granada, Imprenta de Indalecio Ventura, Granada, 1892, p. 70; GaLlEGO Burín, Antonio: La Alhambra, Granada, 1963, p. 133, nota 230. 


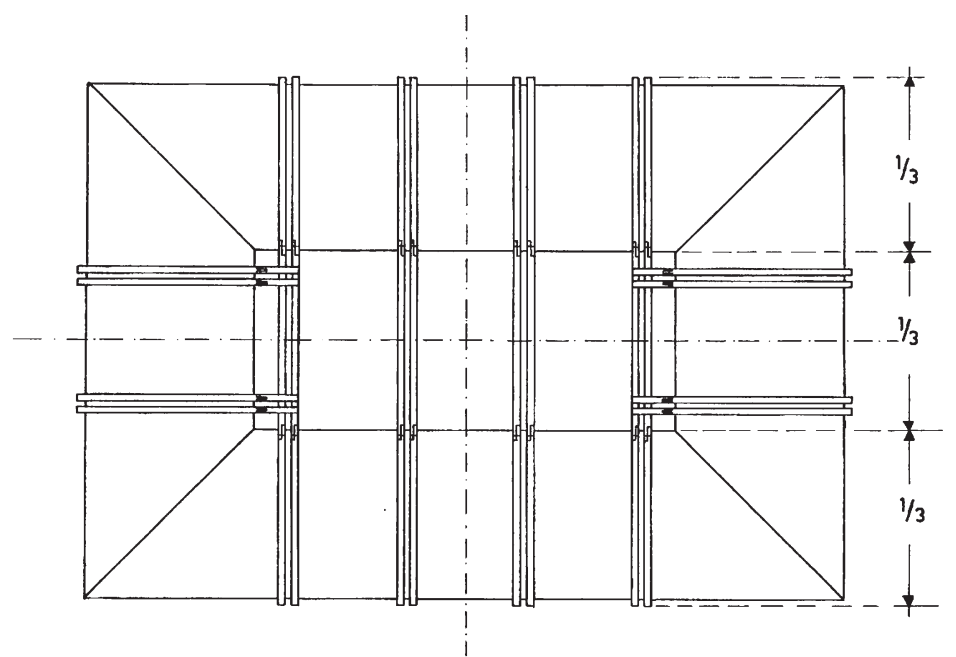

PLANTA DE LA ARMADURA POR SU PARTE SUPERIOR

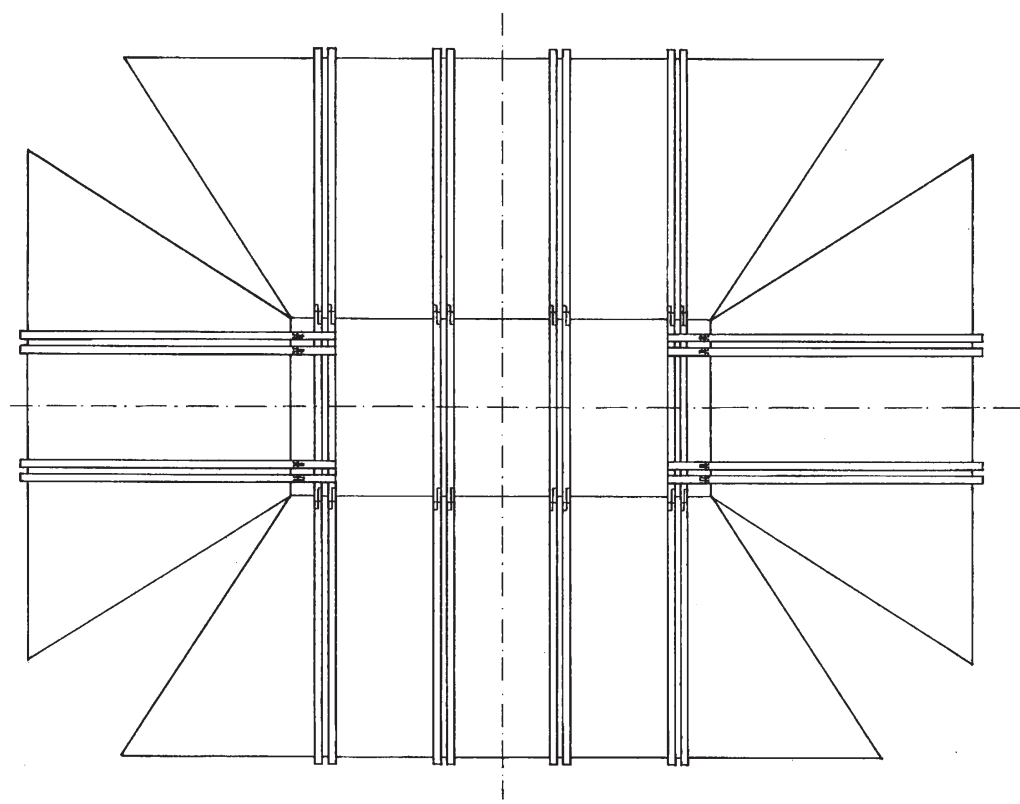

PLANTA DE LA ARMADURA POR SU PARTE SUPERIOR (DESPLEGADA)

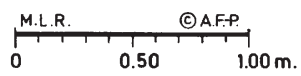

Fig. 17. Armadura apeinazada. Composición del refuerzo de 1853: planta cerrada y abierta por sus ángulos. 


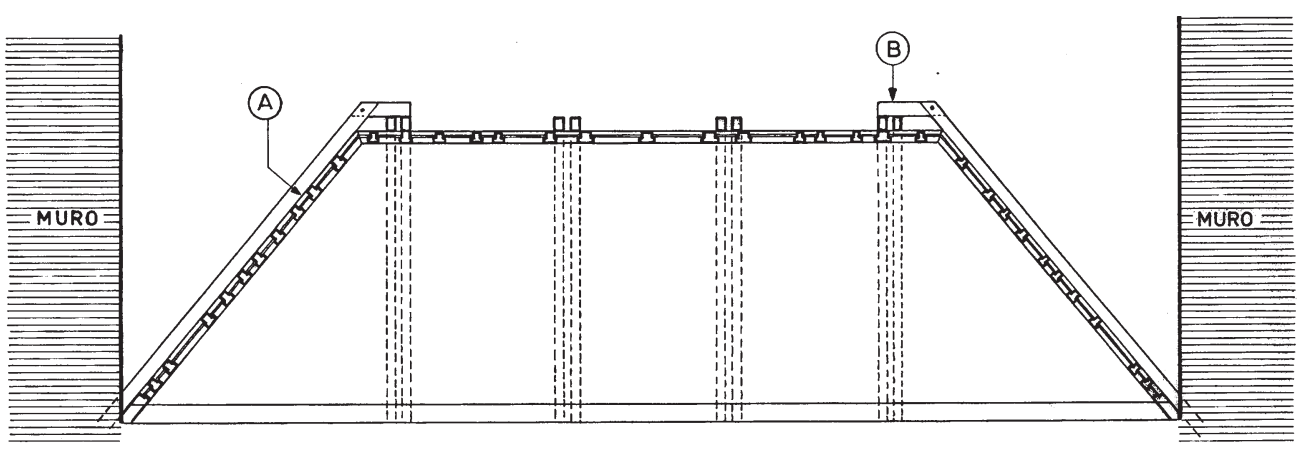

SECCION LONGITUDINAL

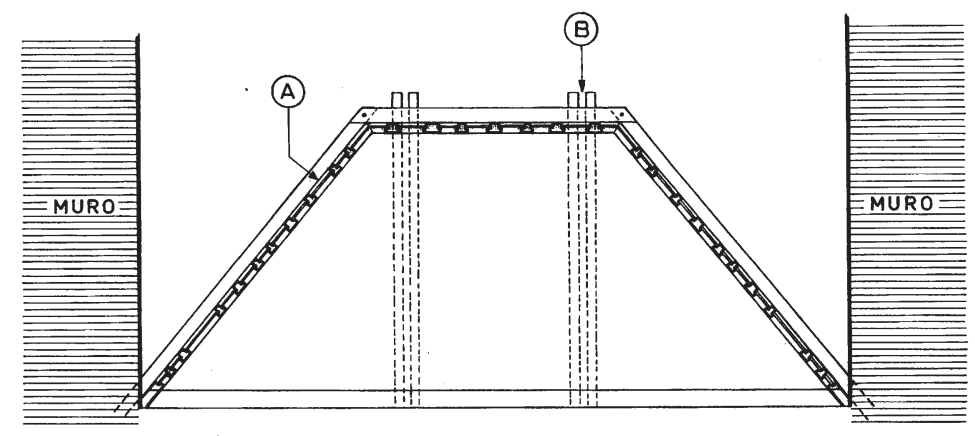

SECCION TRANSVERSAL

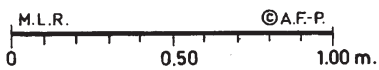

Fig. 18. Secciones longitudinal y transversal de la armadura nazarí y su soporte de 1853 .

dibujo de la sala linterna de la Qubba Mayor y las cenefas de sus yeserías, en la taza de mármol de la fuente de los Leones, en los papos de los tableros de madera de los arriostramientos del patio de los Leones (en la terminología de la carpintería de la Alhambra se les denomina capialzados), etc. ${ }^{12}$. María del Carmen López Pertínez ha señalado que se trata de la única armadura "que conocemos en la que se emplea como tema geométrico decorativo los encintados, generalmente utilizados en alfarjes y conservados en algunos tramos de la galería del Patio de los Leones"13. Este tipo de lazo sencillo de cintas entrecruzadas de colores sobre fondo blanco, lo adoptan los moriscos en sus intervenciones en la Alhambra, así como con otros de extrema complejidad ya que combinan ruedas con estrellas de número impar de puntas $(5,7$ ó 9) con las de número par. Pasemos a ver cómo está organizada la

\footnotetext{
12 Cabanelas, Darío y FernándeZ-Puertas, Antonio: "El poema de la fuente de los Leones", en Cuadernos de la Alhambra, 15-17, 1979-1981, pp. 3-88, figs. 1-56, láms. 1-28; especial. pp. 12, 13, figs. 11-22.

${ }^{13}$ López PertíNez, M. Carmen: La carpintería en la arquitectura nazarí, Fundación Rodríguez-Acosta, Instituto Gómez-Moreno, Granada, 2006, p. 264, fig. 158 en p. 260.
} 
estructura de madera de pino del sostén y refuerzo moderno del trasdós de la armadura decorativa apeinazada del bahw, que ha hecho que llegue hasta nuestros días:

1) Muestra la misma división en tres tercios (fig. 17). En el almizate (al-mīsāṭ o parte central), hay cuatro pares de finas maderas escuadradas paralelas, de 2' $6 \mathrm{~cm}$. por $2^{\prime} 3 \mathrm{~cm}$., dos cerca de los extremos y los otros dos próximos al eje trasversal. Estos pares se unen en los faldones trapezoidales a N. y S. al rebajar la mitad de su grosor y clavarse mediante puntillas (fig. 11.B).

2) Esta estructura moderna tiene en los faldones trapezoidales menores a E. y O. dos pares de análogas finas maderas escuadradas que se machihembran y clavan a maderos que los une de modo horizontal a los de los extremos del almizate, pero no recorrieron éste para evitar la sombra que ocasionarían (figs. 17, 18, 11.B). Si se abre el almizate y sus cuatro paños sobre el suelo se ven los cuatro ángulos tan agudos en las esquinas (fig. 17, armadura desplegada).

3) Desconozco cómo esta estructura se introduce en los cuatro muros, como se indica en las secciones longitudinal y transversal. Sus paños trapezoidales muestran la gran inclinación de la armadura, debido a su trazado proporcional y a las reglas de la carpintería de lo blanco (fig. 18). En la actualidad, por las fotografías parece que hay en la base un zuncho de madera rojiza de pino sobre el que descansa la labor de cintas entrelazadas de la armadura apeinazada (figs. 10, 12). Todo debió de apoyar en una rastra metida en la obra. Desde el suelo del mirador la armadura no causa esta sensación tan inclinada que tiene como si se ve desde su trasdós (figs. 10, 16).

4) En ambas secciones se ha indicado con la letra A las finas maderas escuadradas y con B el trozo de madera que conecta las de los lados E. y O. (o más estrechos de la armadura) con los pares de los extremos de los paños trapezoidales longitudinales, para darle a todo ello una trabazón en la que se pueda sujetar la armadura decorativa nazarí. Pienso que para colocar esta estructura de refuerzo y restaurar dicha armadura en 1853 se hicieron andamios desde el suelo y por las ventanas del camaranchón.

Los peinazos y vidrios de colores. Los peinazos tienen seis ranuras hechas mediante gramil, más anchas las dos centrales que las dos colaterales. En el centro de cada peinazo de madera de pino, discurre una línea de color blanco albayalde y a cada lado dos finas líneas de color rojo minio paralelas a las blancas en su recorrido geométrico (figs. 19-22). Los peinazos restaurados en época moderna carecen de la policromía (fig. 22). Rellenan los huecos entre las cintas que dibujan los peinazos vidrios de colores blanco, azul, verde, amarillo, rojo (color escaso en el vidrio si es original), dispuestos según la simetría de los ejes longitudinal y trasversal de la armadura. Para colocar los vidrios de colores recortados mediante bocados de alicate (al-liqa $\bar{t}=$ la tenaza), según la forma geométrica requerida por el hueco dejado entre la labor de cintas de los peinazos, se usó un ingenioso método (fig. 11.A). Por la cara trasera del peinazo con sus ranuras se le practicó unos rebajes en ángulo recto y se adosó a la madera una tela pegada, que serviría no sólo para sujetar el vidrio, sino como almohadilla de descanso. Tras ello se le colocaría, por encima del vidrio y de la tela y hasta la madera, una masilla para su sujeción (que pudo ser también yeso fino blanco echado a hilo). Esto hay que comprobarlo cuando se restaure la armadura decorativa apeinazada. Se conoce por documentación de archivo que los vidrios de esta armadura ornamental fueron restaurados en el siglo XVI por los mismos artistas que hicieron las vidrieras de la Catedral de Granada, como Juan del Campo ${ }^{14}$. ¿Hasta dónde llegó la recolocación de

${ }^{14}$ Documentación que nos mostró a Earl E. Rosenthal, a María Angustias Moreno Olmedo y a mí el fallecido amigo Manuel Garzón Pareja de un trabajo que preparaba sobre el tema y con motivo de la publicación del libro de la Catedral por dicho investigador norteamericano. Este dato sobre el vidriero de la Catedral, Juan del Campo, que trabajó restaurando los vidrios de la Alhambra, me lo ha vuelto a facilitar Isabel Cambil Campaña. Trata de este vidriero NIETO AlCAIDE, Víctor: Las vidrieras de la Catedral de Granada, Universidad de Granada, 1973; en su libro La vidriera española. Ocho siglos de luz, Nerea, 1998, pp. 114-117, describe la armadura del bahw. En carta desde Londres contesté a 


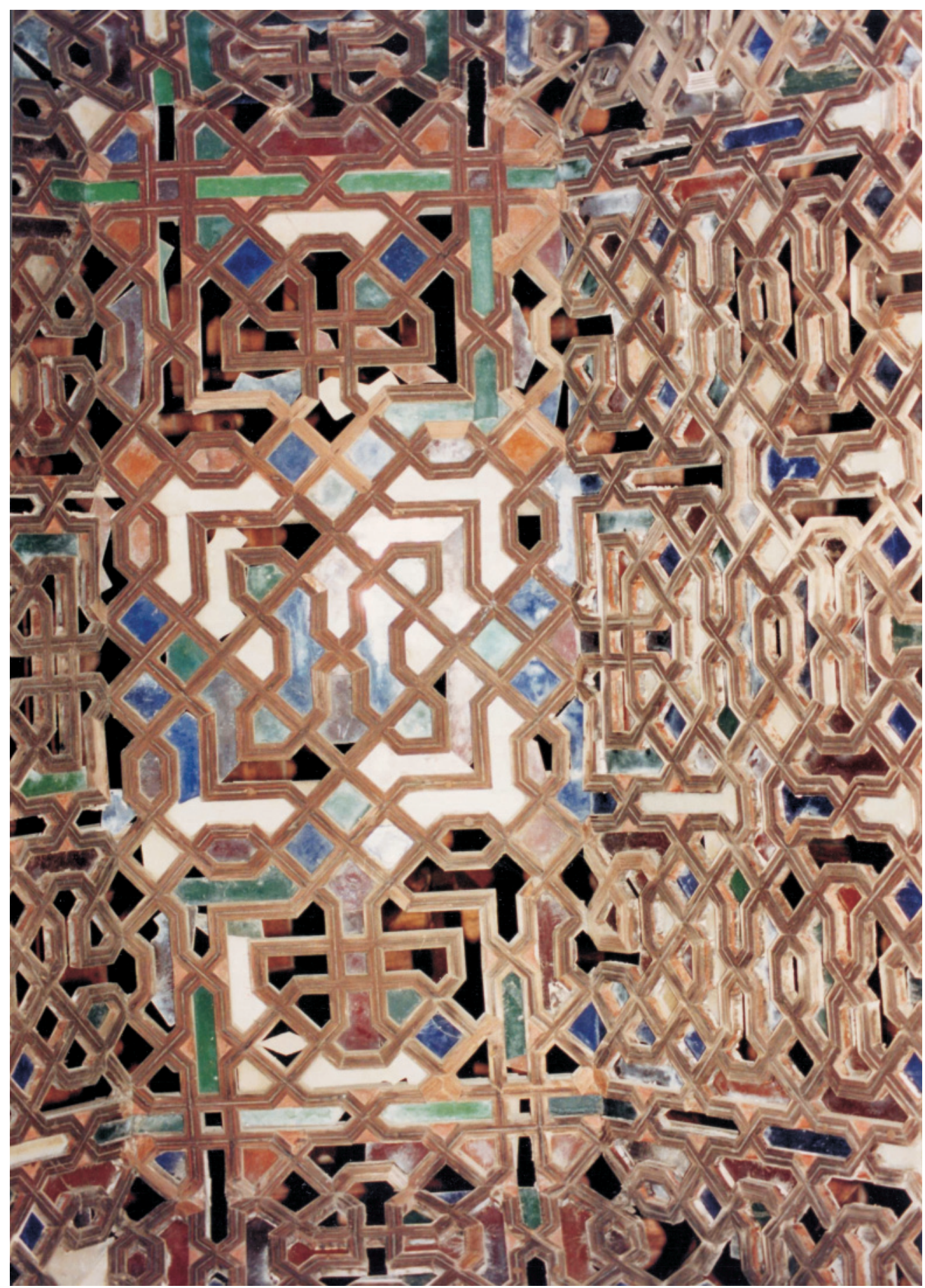

Fig. 19. Almizate o parte central de la armadura apeinazada con vidrios. 
vidrios en sus huecos o se pusieron nuevos en la restauración de 1853 por Rafael Contreras? Sólo se sabrá con seguridad cuando se restaure y estudie uno por uno los cientos de piezas, aunque los que yo he examinado son todos modernos por la técnica. Hay que hacer notar que los diferentes colores de los vidrios se corresponden con el de las cintas de los alicatados, en las cuales no aparece el color rojo. El color púrpura aparece bajo Yūsuf I en su Qalahurra Nueva (1348) en composiciones de ruedas de lazo (panel de alicatado del Museo de la Alhambra, R.E. 4588) y en un ápice de letra cúfica procedente de la Alcazaba de Málaga (R.E. 4632). Luego, el vidrio rojo de la armadura fue colocado en 1853.

En el arte nazarí, las armaduras apeinazadas de cintas con vidrios de colores aparecen bajo el sultanato de Muhammad V, y no antes, según mis conocimientos actuales. En 1362, su gran visir Ibn al-Jațīb, relata en su obra la Nufäda III que se celebró la festividad de la natividad del Profeta, o mawlid en el Nuevo Mexuar que estaba construyendo el soberano en el Qașr al-Sultān (= palacio de Comares). Al describir la estancia de la Alta Qubba donde el soberano tenía su trono (hoy la sala llamada del Mexuar), dice que la qubba "sobresalía por encima del resto de lo techado. La

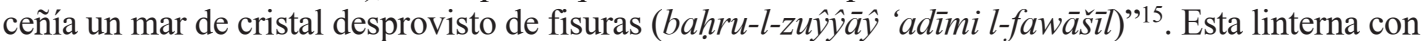
su armadura desapareció cuando la parte alta del Mexuar se convirtió en un área de la Casa Real de los Reyes Católicos a partir de 1492. En el Alcázar al-Riyāḍ se encuentra en la armadura que aquí se estudia y alude a ella el poema de las tacas fingidas en el intradós de su arco de acceso de mocárabes; el verso 2 de la jamba O., a la izquierda, dice: "Este alcázar de vidrio [șarḥu-l-zuŷȳây], quien lo mira con detenimiento / cree que es la profundidad del mar a la que tiene miedo y pavor". Es una buena descripción metafórica del efecto que causaría la luz al atravesar los vidrios de distintos colores de la armadura apeinazada y los de los perdidos ajimeces de las tres ventanas ${ }^{16}$.

El tercer alcázar-almunia donde Muhammad V utilizó vidrio ensamblado a peinazos, fue su palacio de los Alijares. Entre 1448 y 1450 describió Ibn 'Āṣim que en las puertas $(a b w a \bar{a} b)$ del alcázar de los Alijares hubo numerosas pantallas solares de vidrio (bi-'a'dāadi l-šamsiyyāt alzaŷâyiyya) para iluminar el paso de la entrada ${ }^{17}$. En las excavaciones de los Alijares (1890-1891)

sus preguntas sobre esta armadura y le facilité los datos técnicos que tenía a mano como dice en la nota 83 en p. 363 el apreciado amigo y colega: "Agradezco sinceramente al profesor A. Fernández Puertas las fotografias y la información enviada sobre las vidrieras del Mirador de Lindaraja". La luz, símbolo y sistema visual (el espacio y la luz en el arte

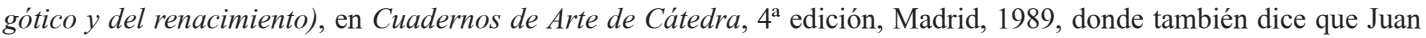
del Campo trabaja en la Catedral para terminar las vidrieras de 1552 a 1554. La vidriera del renacimiento en Granada, Diputación de Granada, 2002, p. 27.

${ }^{15}$ Ibn al-Jațīb, Nufạdat al-ŷirāb fì 'ulālat al-igtirāb, parte III, ed. al-Sa'adiya Fāgiya, Casablanca, 1989, p. 275. Manuscrito de Leiden: Golius. Ms. 11 (1). Biblioteca de la Universidad de Leiden, folio 20a, línea 7, palabra 6.

${ }^{16}$ Alonso del CASTILLO, en su Manuscrito, $\mathrm{n}^{\circ} 7.453$ de la Biblioteca Nacional de Madrid, folio 10r, líneas 6 y 7, traduce "Este es el alcázar del vidrio". Le sigue LAFUENTE y ALCÁNTARA, E.: Inscripciones árabes de Granada, edición facsímil con Estudio preliminar de María Jesús Rubiera, Colección Archivum, nº 81, Universidad de Granada, 2000, p. 137, nota b en la que dice "Alude el poeta al palacio de cristal de Salomón, de que habla la sura 27 del Corán, y que la reina de Sabá creía que era un océano (ver 44)". GARCía Gómez, E.: Poemas árabes en los muros y fuentes de la Alhambra, Publicaciones del Instituto Egipcio de Estudios Islámicos en Madrid, Madrid, 1985, pp. 122, 123, lee șarhu-l-zuŷŷây pero traduce "un suelo de cristal"; para que signifique "suelo" el vocablo tenía que ser femenino, șarḥa. Recoge la alusión coránica que da Lafuente y Alcántara pero indica que el "texto no alude necesariamente a una alberca desaparecida. Basta pensar en la gran taza de la fuente [Lindaraja], puesta por tierra o enterrada a ras de tierra". Creo que este estudio del bahw con su armadura apeinazada de cintas con vidrio, como lo fueron los cierres de sus tres ajimeces, explica muy bien la traducción de "Alcázar de vidrio", sin que tengamos que recurrir a metáforas salomónicas y sentido esotérico en este palacio de un sultán ortodoxo mālikī.

17 Abū Yaḥyà Muḥammad ibn 'Āṣim al-Garnātī, Ŷannat al-rị̣à' fì l-taslīm li-mā qaddara Allāh wa-qaḍa, ed. Salāḥ Ŷarrar, Dār al-Bašīr, Jerusalem-“Ammān, 1989, pp. 24-29, especial. p. 28; línea 9. El título también puede ser Ŷunnat al-riḍā'. FernáNDEZ-Puertas, A.: "El Alcázar al-Dišār [los Alijares]”, en In Sapientia Libertas, escritos en homenaje al profesor Alfonso E. Pérez Sánchez, Madrid-Sevilla, Museo Nacional del Prado, Fundación Focus-Abengoa, 2007, pp. 113-128, especial. 113, 115. 


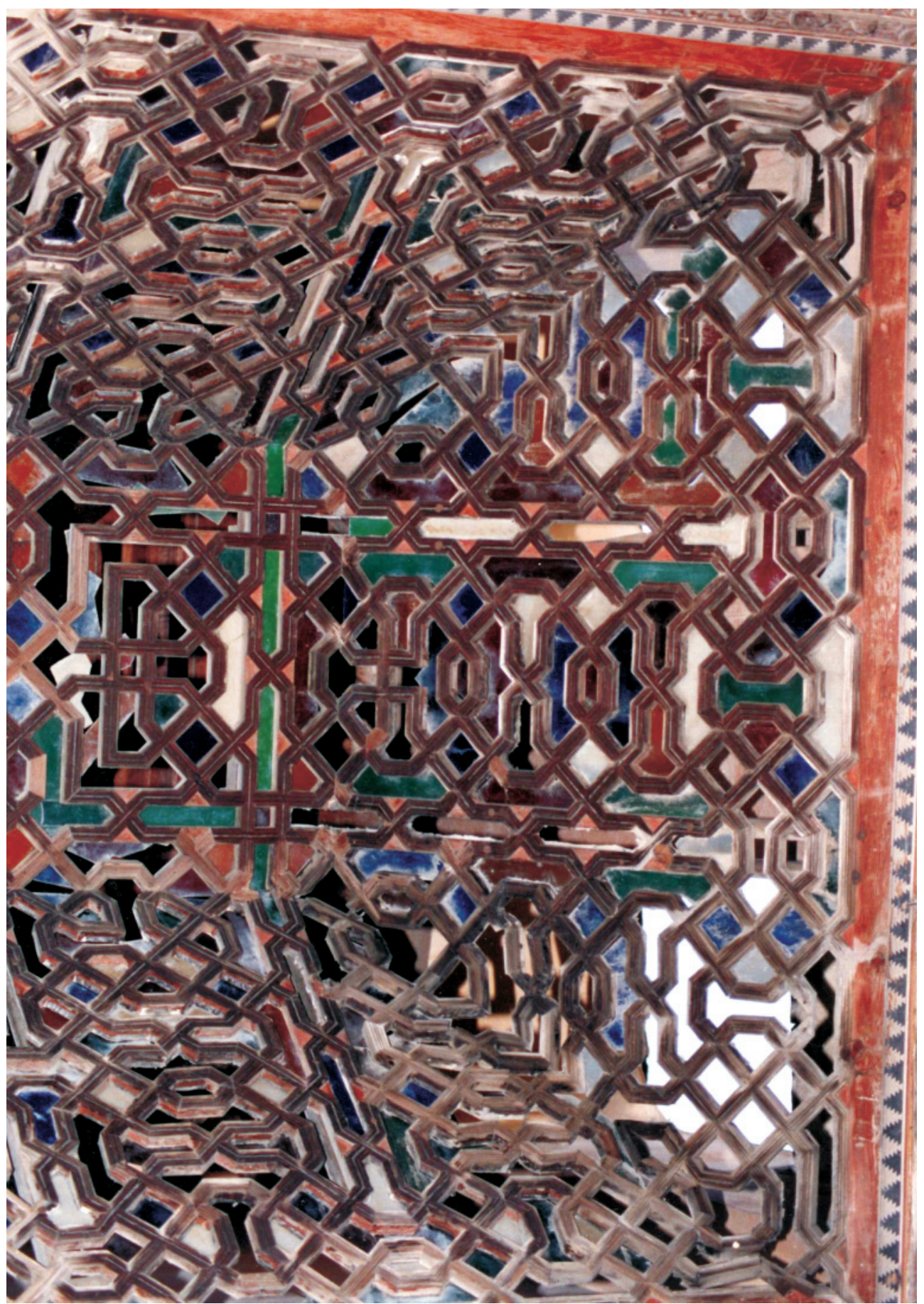

Fig. 20. Armadura apeinazada. Lados trapezoidales cortos de E. y O. 


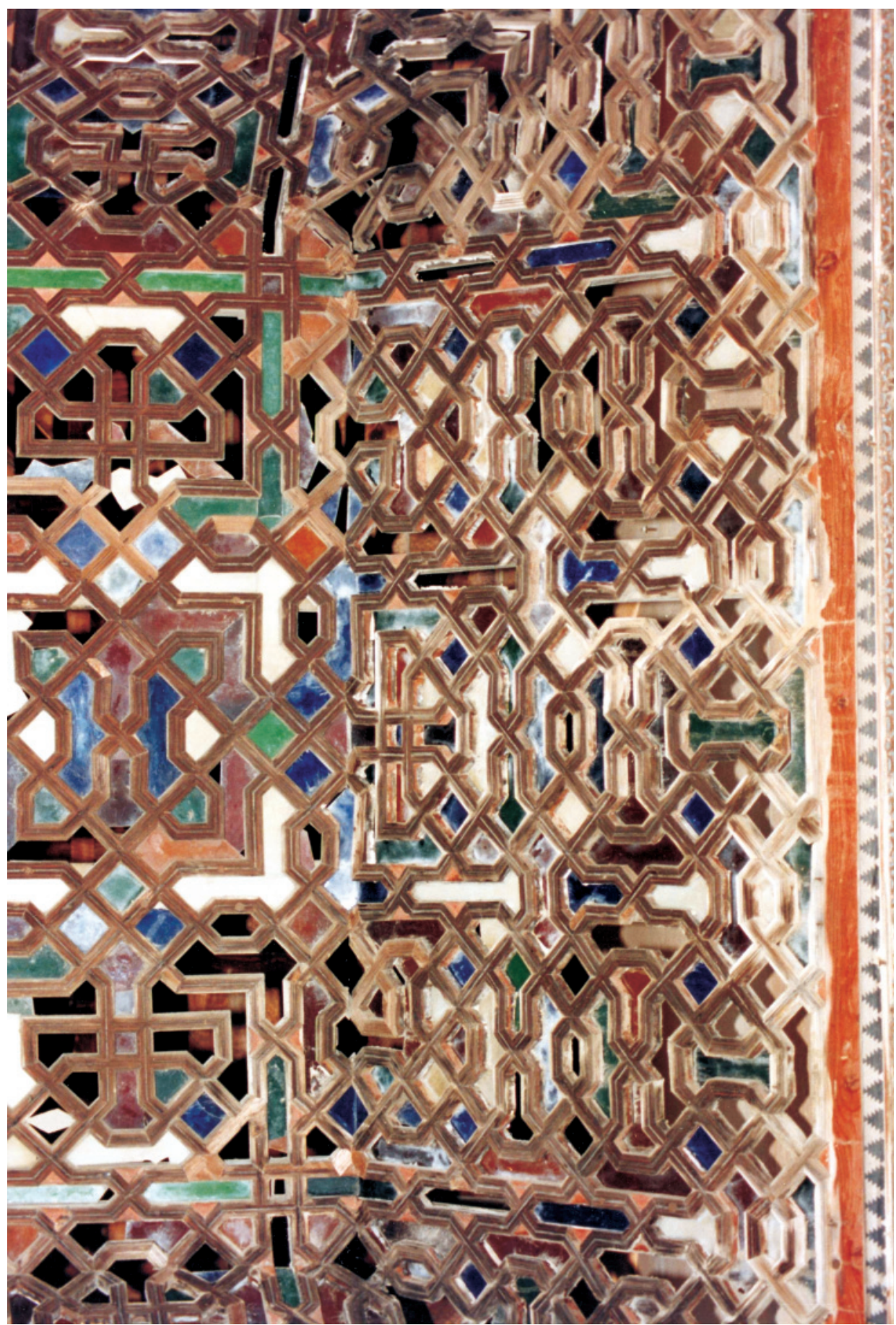

Fig. 21. Armadura apeinazada de los lados trapezoidales longitudinales N. y S. 


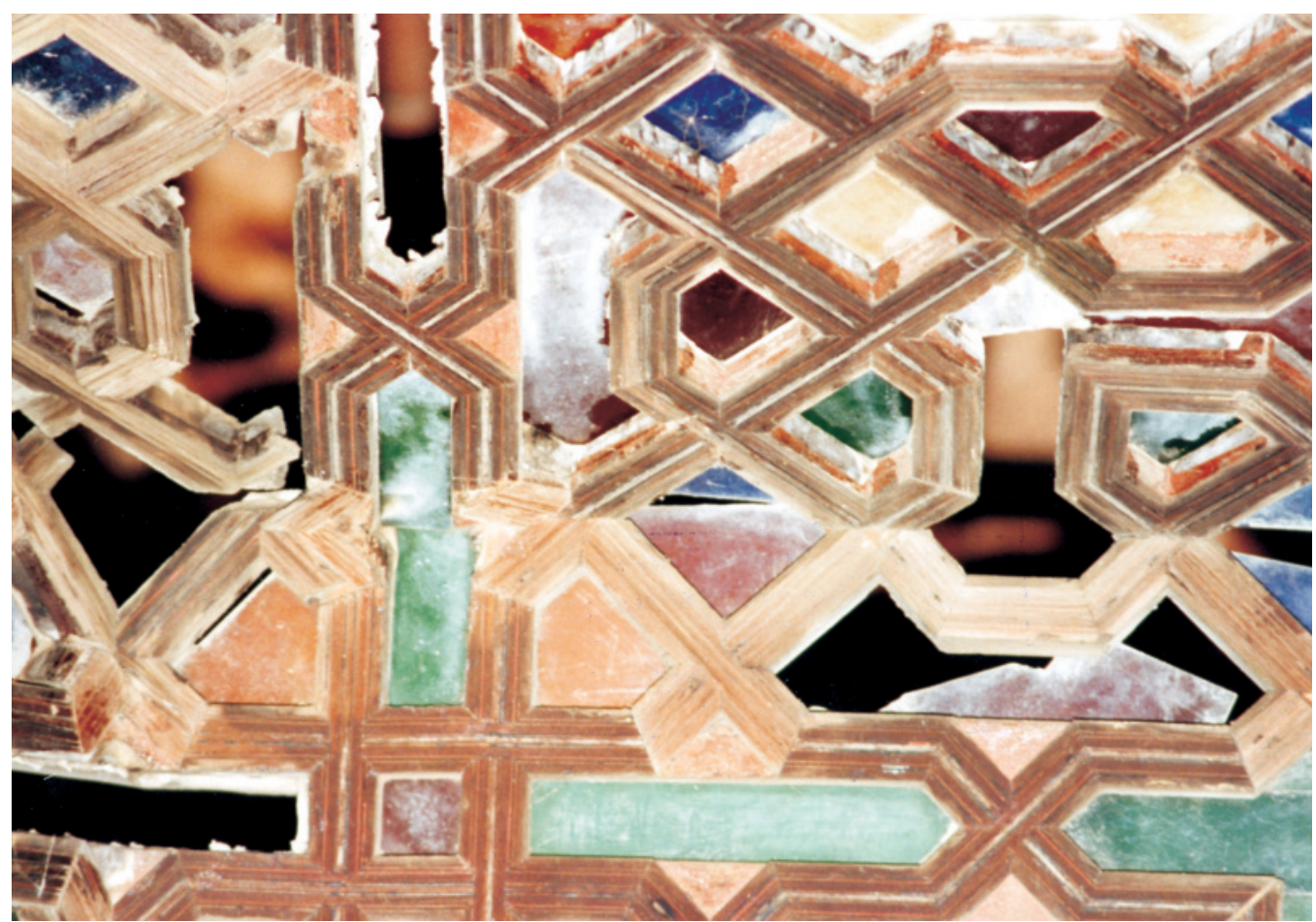

Fig. 22. Detalle de la policromía de las cintas agramiladas de los peinazos.

se hallaron fragmentos de vidrios que pertenecieron a un mirador o bahw que se hallaba en la parte E. de la almunia, fuera del palacio, y que daba hacia la Vega y Sierra Nevada (de modo similar a la torre de Abū l-Ŷyŷū̌s que mira hacia Granada y al N. en el palacio del Riyāḍ al-Sa'īd). Una parte de estos vidrios se encuentra en la Colección Gómez-Moreno y otra en el Museo Arqueológico Provincial de Granada ${ }^{18}$.

De las técnicas usadas en el vidrio arquitectónico, la más abundante en lo nazarí es la llamada "soplado en corona"19, que consiste en extraer la masa vítrea al rojo derretida desde el crisol mediante una vara y girarla hasta abrirla en un círculo, de ahí su nombre. Cuando éste está frío se cortan las piezas tras dibujarlas. Ésta es la técnica más frecuente en los vidrios nazaríes destinados para la arquitectura ${ }^{20}$.

Cuando limpié y organicé los fondos del Museo de la Alhambra, entre 1978 y 1984, encontré en dos grandes cajones con asas de soga, una considerable cantidad de vidrios de colores que se

18 Gómez-Moreno, M.: Guía de Granada, pp. 175-177. A. Fernández-Puertas, "El Alcázar al-Dišār [los Alijares]", p. 118, nota 10 en p. 128.

19 Aparte de esta técnica existen desde época romana otras como la llamada "colada" y la denominada por su obtención técnica de "cilindro".

${ }^{20}$ CAmbil CAmpaña, Isabel: "Vidrio arquitectónico en la Alhambra", en ciclo La pieza del mes en el Museo de la Alhambra, junio 2006. Purificación Marinetto Sánchez e Isabel Cambil Campaña, "Números 106-118. Vidrio de celosía. Museo de la Alhambra", en catálogo Vidrio Islámico en al-Andalus, Real Fábrica de Cristales de la Granja, noviembre de 2006-abril de 2007, Junta de Castilla y León, pp. 156-160, lám. en p. 156. 

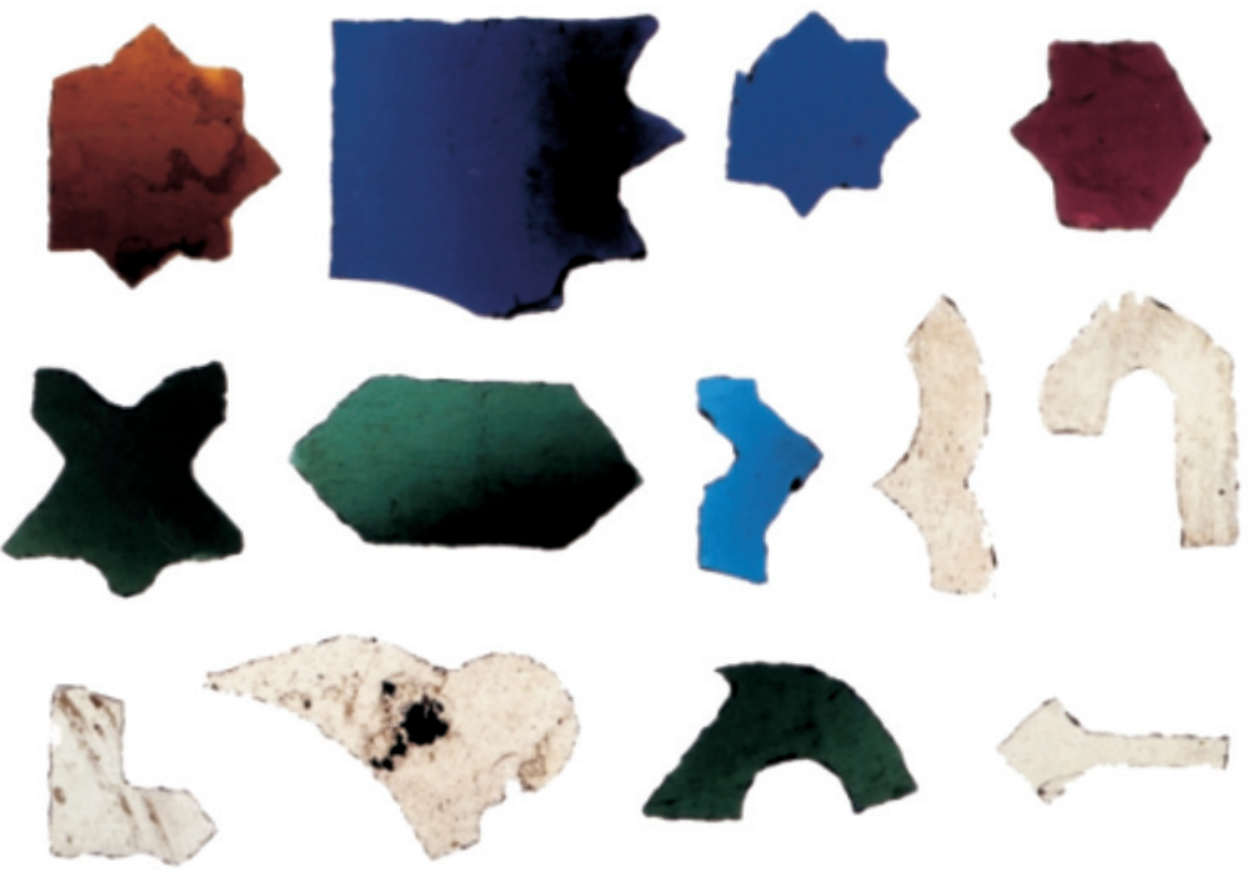

Fig. 23. Piezas de vidrio de celosías conservadas en el Museo de la Alhambra.

desempolvó y clasificó. María del Carmen Melero Rodríguez empezó a estudiar el vidrio de ajuar $^{21}$.

En el vidrio con uso arquitectónico (fig. 23), hallé que había tres formas bien definidas: a) Cortadas en cintas quebradas en ángulos, más o menos finas, al menos de dos o tres anchos, similares en forma a las del bahw de la Qubba Mayor, que se utilizarían para los postigos de las ventanas y cierres de las salas y demás estancias; igualmente cintas lobuladas. b) Vidrios cortados en forma de polígonos para formar ruedas como estrellas, almendrillas, zafates, candilejos, costadillos y demás formas que las componen, como aparecen en las yeserías caladas de las celosías de cierre de las estancias por encima de los arcos de acceso, ventanas altas de sus alcobas (salón de Comares), o las ventanas altas de los cuerpos lucernarios de las salas y qubbas. c) Vidrio cortado en forma de palma de dos hojas o ataurique ${ }^{22}$.

Los ajimeces ( al-šimāsa), balcones o cierres volados ${ }^{23}$, y las ventanas de cierre con vidrios y contraventanas $^{24}$ debieron tener una estructura de maderas apeinazadas y entre sus huecos geométricos vidrios de colores, ya diseñando lazo de cintas ya dibujando lazo de ruedas. Las

${ }^{21}$ Melero Rodríguez, María del Carmen: “Análisis tipológico del vidrio nazarí de la Alhambra”, Estudios dedicados a don Jesús Bermúdez Pareja, Asociación Cultural de Amigos del Museo Hispanomusulmán, Granada, 1988, pp. 71-94. Este tema fue el motivo de su Memoria de Licenciatura, muy bien elaborada, El perfume en la cuenca del Mediterráneo según la literatura. Los vidrios islámicos del Museo Nacional de Arte Hispanomusulmán, Granada, 1982.

22 Marinetto Sánchez, P. y CAmbil Campaña, I.: "Números 106-118. Vidrio de celosía. Museo de la Alhambra", pp. 156-160, lám. en p. 156. El fragmento de celosía con forma de palma de dos hojas tiene el no de registro 14.985; sus dimensiones son de $8 \times 5 \mathrm{~cm}$. con un grosor de 0,15 a $0,25 \mathrm{~cm}$. Es el $\mathrm{n}^{\mathrm{o}} 116$ del catálogo, p. 160 .

${ }^{23}$ L. Torres Balbás, “Ajimeces”, en Al-Andalus, XII, 1947, pp. 415-427.

${ }^{24}$ L. Torres Balbás, "Ventanas con vidrios de colores en los edificios hispanomusulmanes", en Al-Andalus, XIV, 1949, pp. 197-201. No menciona esta armadura decorativa apeinazada con vidrios, ni en éste ni en el anterior trabajo. 


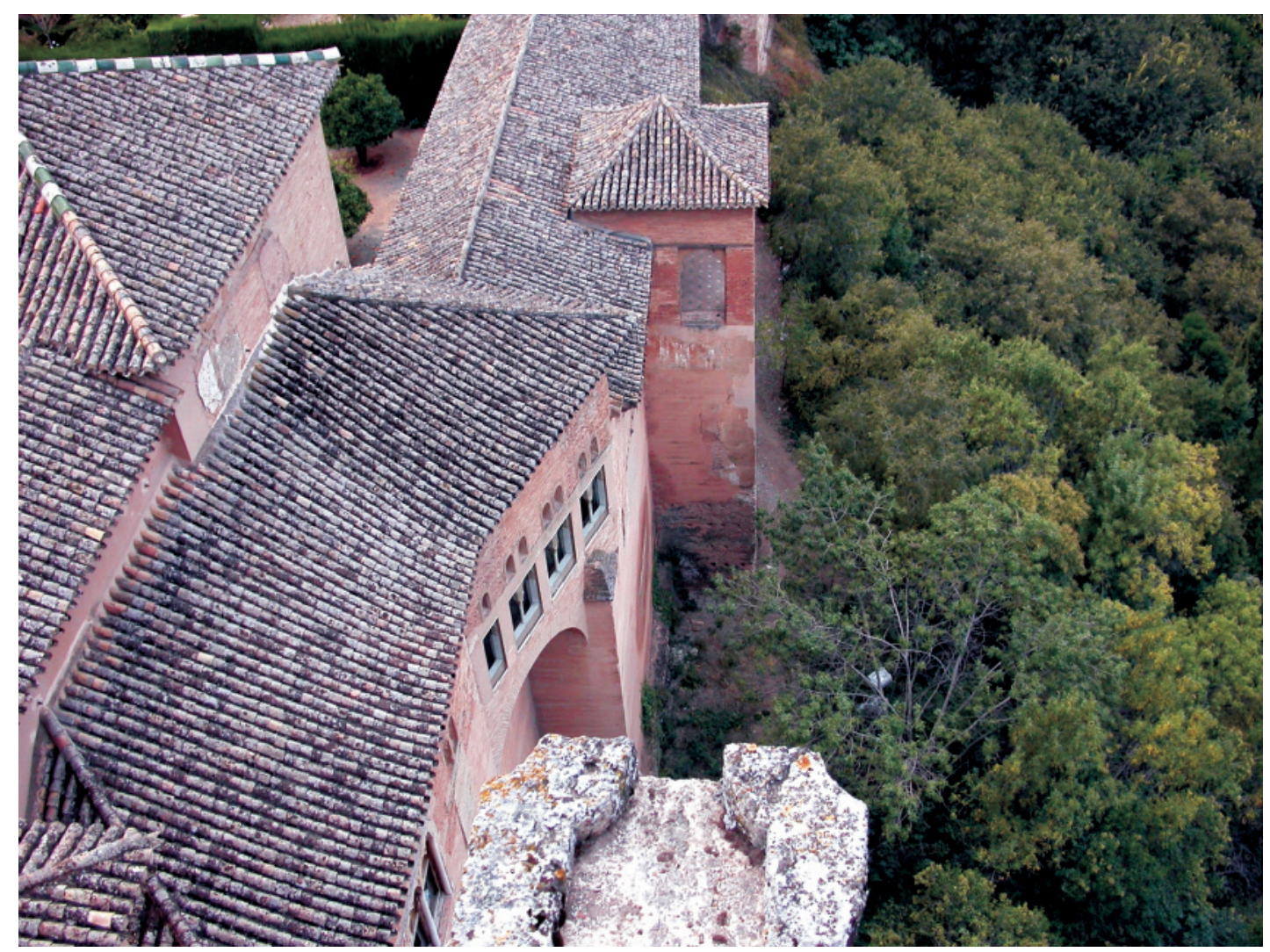

Fig. 24. Vista del Bahw al-Nașr y su galería, del oratorio anexo al Mexuar y Cuarto Dorado.

ventanas y celosías con vidrios cerrarían y aislarían las estancias de las casas y palacios del frío, el calor, el viento, el polvo, y mantendrían el interior recogido, limpio e íntimo cuando dieran a espacios con vistas al exterior. Así estarían en el palacio del Riyāọ al-Sa'īid en las ventanas cerradas de este mismo bahw o mirador, en los ajimeces de los arcos dobles sobre columna parteluz de la sala de los Ajimeces, en los bahws altos de la galería N. y S. del patio de los Leones, y en las celosías altas de yesería de las qubbas-linternas de sus salas. Las ventanas altas de la sala linterna de la Qubba Mayor tienen un bastidor, o marco de madera, hacia el lado de la estancia, con el perfil de los mocárabes colgantes de la bóveda, que debió de sostener una celosía de vidrios hoy perdidos. No sé si el bastidor está metido en la obra medieval nazarí o se encuentra superpuesto desde época renacentista, pues esta sala sirvió de comedor al emperador en su estancia en Granada de mayo a diciembre de 1526, como especifica el Plano de Pedro Machuca, que fecho en 1542, guardado en el Palacio Real de Madrid por adquisición de Alfonso XIII en 1911. En el palacio de Comares estuvieron unidas las hojas de ventana con cristales a las celosías en las nueve alcobas del salón del Trono y los vidrios incrustados en las yeserías de rueda de sus ventanas altas. L. Torres Balbás encontró al pie de la Torre de Comares vidrios de colores caídos de las ventanas y celosías ${ }^{25}$. Manuel López Reche al dibujarlas mediante andamio en 1958-1959

25 Torres BalbÁs, L. "Ventanas con vidrios", p. 200. Los dejó en los fondos del Museo de la Alhambra, desgraciadamente sin identificar como tantas cosas, y que el personal antiguo adepto al Monumento ha ayudado a identificar en muchas ocasiones, como el maestro de obras José Torres Martínez. 


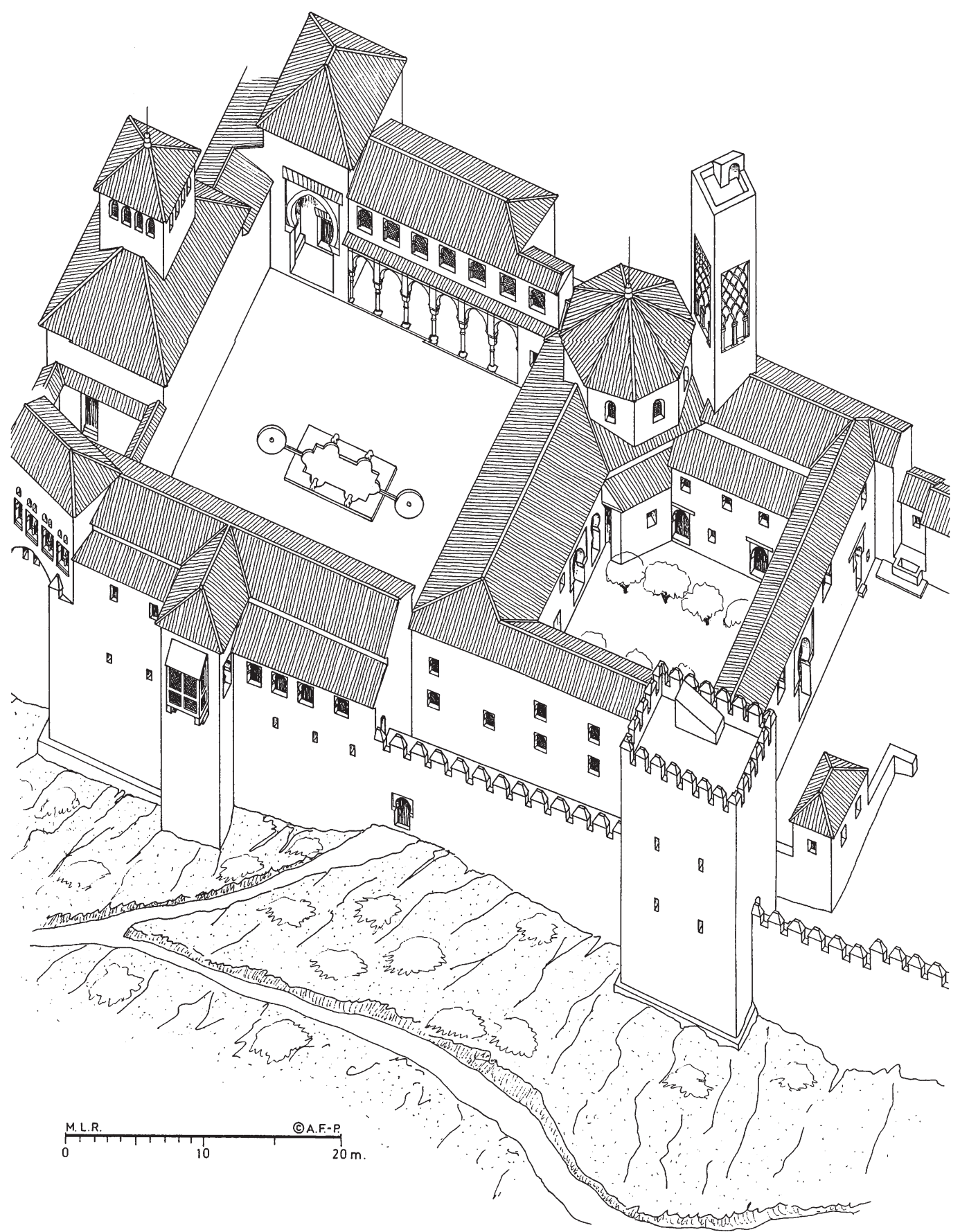

Fig. 25. Dibujo axionométrico restitutivo del Mexuar: Mexuar primero con la mezquita y el alminar; Mexuar segundo con el zafariche y el Bahw al-Nașr; la Qubba alta del trono (hoy el Mexuar). 
llegó a ver los restos de sus bastidores. En el bayt donde el soberano residía (hoy llamado sala de la Barca), las celosías hacia la galería N. tuvieron vidrieras que en época cristiana se repusieron por otras formando una trama de octógonos con cuadraditos entre ellos, según se ve en grabados como el de Lewis ${ }^{26}$. En 1973, inspeccioné con escalera las tres ventanas hacia el interior de la sala y encontré los restos del bastidor cristiano y arranque de estos vidrios emplomados en sus partes verticales laterales. Las ventanas de las crujías E. y O. del patio de Comares y de la fachada de Comares tuvieron celosías y hojas de ventanas con vidrio.

Los arcos E. y O. del Bahw al-Nașr (hoy conocido como torre de Machuca) tienen resto de celosías, pero las hojas de sus ventanas con vidrio no se han conservado. En su ventana N. hubo un volado ajimez soportado a cada lado por dos gruesas vigas superpuestas escalonadas (fig. 25), que L. Torres Balbás restituyó al encontrar los enormes mechinales rectangulares en el hormigón de la torre, como un balcón volado con terraza, según se ve en las fotografías de Torres Molina. Francisco Prieto-Moreno Pardo lo tuvo que suprimir porque se pudrieron las maderas con que L. Torres Balbás lo había construido, ya que el suelo de la terraza se embalsaba con el agua de la lluvia. No dejó abiertos los mechinales para que no anidara cualquier tipo de ave, pero, debió de dejar marcada la huella de los huecos en el muro N., por lo cual hoy han quedado invisibles (fig. 25).

Así, pues, la importancia de esta armadura decorativa apeinazada es del máximo interés, aunque sus vidrios de colores sean en buena parte modernos. No queda más que este ejemplar de la carpintería ornamental hispanomusulmana, y se encuentra en muy mal estado de conservación, a pesar de las intervenciones que se pueden ver a simple vista en sus peinazos y en la estructura de 1853 de sujeción, momento en el que se repusieron la mayoría de sus vidrios. Al no tener celosías las ventanas altas del cuerpo lucernario (figs. 1, 8, 9, 16), todo tipo de pájaros, palomas, insectos, etc., así como los fuertes vientos o ráfagas de éstos con lluvia y el constante polvo y contaminación han provocado una enorme capa de suciedad y un constante deterioro en el trasdós de esta armadura (fig. 16). Además, la acumulación del polvo, la tierra caída del tejado estructural y la lluvia que le entra forman una capa de barro seco, más o menos espesa, que evita que la luz traspase los vidrios y tapa el trasdós de los peinazos de madera. La claridad llega más por donde no hay vidrios y mutilaciones de los peinazos. Los vidrios, al desprenderse, se han caído y se han deslizado por fortuna a la base de los cuatro faldones trapezoidales de la armadura (fig. 16).

Tanto los peinazos de esquina como los de la base de la armadura o están rotos o podridos o mutilados sobre el zuncho de madera de pino rojo colocado cuando se hizo la restauración en 1853 (figs. 10, 12, 19-20). Es necesaria una rápida e inminente restauración y saneamiento con limpieza de los peinazos, vidrios, fijación de su policromía, antes de que sea inevitable su pérdida, pues cualquier causa inesperada, como una mayor pudrición de sus peinazos, un ligero movimiento sísmico, el estruendo de una fuerte tormenta, etc., puede hacer que se arruine para siempre este objeto de arte único y caiga al suelo y se haga añicos. Cuando se efectúe la restauración se podrá hacer un estudio exhaustivo de la armadura y la historia de sus restauraciones. Me consta que la actual dirección del actual Patronato está preocupada por el tema. Esperemos ver pronto la deseada restauración de esta magnífica armadura decorativa apeinazada entre cuyas cintas hay vidrios que dejan pasar la luz cenital. En mi opinión, esta labor la debe realizar el taller de restauración especializado en madera y policromía del Patronato de la Alhambra, cuyo trabajo conozco personalmente desde 1967. No es un trabajo para darlo a una contrata, como es lo normal en la Administración en la actualidad.

Fecha de recepción: 20-IV-2009

Fecha de aceptación: 03-VI-2009

${ }^{26}$ LEwIS, J. F.: Sketches and drawings of the Alhambra, Londres, 1833-34. 